\title{
The Model of the Optimal Number of Public Transport Vehicles in Mixed Traffic Flow Conditions: A Case Study
}

\author{
Milja M. Simeunović $\mathbb{D}^{1},{ }^{1}$ Vuk Z. Bogdanović $\left(\mathbb{D},{ }^{1}\right.$ Milan M. Simeunović $\mathbb{D}^{1}{ }^{1}$ \\ Pavle M. Pitka $\mathbb{D}^{1}{ }^{1}$ Zoran M. Papić $\mathbb{D}^{1},{ }^{1}$ and Dane M. Drašković $\mathbb{D}^{2}$ \\ ${ }^{1}$ Faculty of Technical Sciences, University of Novi Sad, Trg Dositeja Obradovića 6, 21000 Novi Sad, Serbia \\ ${ }^{2}$ Pan-European University Apeiron, Banja Luka 78000, Bosnia and Herzegovina \\ Correspondence should be addressed to Pavle M. Pitka; pitka@uns.ac.rs
}

Received 11 June 2021; Revised 7 July 2021; Accepted 6 August 2021; Published 18 August 2021

Academic Editor: Dragan Z. Marinkovic

Copyright (C) 2021 Milja M. Simeunović et al. This is an open access article distributed under the Creative Commons Attribution License, which permits unrestricted use, distribution, and reproduction in any medium, provided the original work is properly cited.

\begin{abstract}
Bus passenger transport is very important for sustainable urban mobility, and due to the characteristics of the street network, it is usually realized in the conditions of mixed traffic flow. Disturbances and sudden changes of traffic flow parameters occurring in the street network in a mixed traffic flow affect the disruptions in schedule and travel time of all vehicles in the traffic flow, including public transport (PT) vehicles. In order to keep to the planned schedule in the peak hours of PT lines carried out in the conditions of mixed traffic flow, the operators introduce new vehicles or reduce the vehicles' dwell time at terminuses, which is often impossible to do. The use of a larger number of public transport vehicles increases the fuel consumption, pollutants' emission, and the operating costs. In this paper, a network optimization model was developed for defining the influence of the change of traffic flow parameters in a mixed traffic flow on travel time of PT vehicles. The model takes into consideration uncertain time unevenness of the change of traffic flow parameters, which enables determining the optimization of travel time and defining the necessary number of public transport vehicles for the purpose of keeping to the planned schedule. In order to develop the transport model, counting and analysis of the characteristics of traffic flow at 61 intersections on the city territory were carried out. The model was tested on bus line number 4 of PT in Novi Sad. The model showed that it is possible to achieve certain savings regarding the number of vehicles with the unchanged headway, that is, the unchanged level of service which is offered to the users. With the application of the model in real traffic conditions, significant savings, as well as operating and external costs' reduction, can be achieved, which contributes to the sustainability of public bus transport in urban environments.
\end{abstract}

\section{Introduction}

Efficient and well developed public transport represents the most important segment of the sustainable urban mobility $[1,2]$, and in many cities it is based on the surface, which is most commonly bus transport. Bus transport does not demand huge infrastructure investments and has much higher flexibility in relation to rail systems of public transport, which is its basic and very important comparative advantage. European Automobile Manufacturers' Association (ACEA) reported that $55.7 \%$ of passengers in public transport are transported by buses, out of which, according to the International Association of Public Transport (UITP),
$67 \%$ are typical buses [3]. According to the available data, the transport sector contributes one-quarter of global emissions with the greenhouse effect [4], and the research studies carried out in Novi Sad showed that around $16.3 \%$ of $\mathrm{CO} 2$ emission originates from public transport vehicles, although they participate in the traffic flow with less than 5\% [5]. In order to reduce the emission of pollutants, it is very significant to advance the public transport system, not only by introducing new environmentally acceptable vehicles into the system, but also by introducing some operating measures in order to increase the efficiency. Namely, according to ACEA, only $2 \%$ of buses in Europe use alternative fuels, and the average age of the bus is 11.4 years. Nesheli at al. [6] 
suggested in their paper operating tactics in real time, which will enable more efficient management of public transport system, thus contributing to the sustainable transport, that is, affecting the reduction of energy consumption and thus pollutants emission. Public transport has to be balanced and integrated into the city transport network, because in that way it will be placed within sustainable, that is, environmentally acceptable, frameworks.

Many cities, respecting the principles of sustainable urban mobility, take different measures in order to increase the accuracy and efficiency of bus traffic in public transport, first of all by forming special traffic lanes for buses and giving the priority to public transport buses at intersections. However, due to the inherited urban structure and the characteristics of the street network, the largest number of bus lines of public transport are carried out in the conditions of mixed traffic flows. For this reason, especially in peak hours, schedule deviation and disruption occur. In order to maintain the transport quality, primarily accuracy of the arrival to the bus stops, the operators take different measures. Certain deviations, that is, delays, can be corrected by reducing dwell time at terminuses, but this measure has limited possibilities. Namely, terminus dwell time has been optimized and harmonized with legal requirements regarding drivers' rest, which represents a restriction and a risk in case minimal necessary time gaps are obeyed. For this reason, operators solve the disruptions in the timetable caused by unfavorable traffic conditions by introducing new vehicles into the lines of public transport.

In many cities, it is not possible to determine travel time precisely due to the fact that the traffic is performed in interrupted traffic flow conditions. Occasionally, interrupted traffic flows are those where the conditions of vehicles motion, apart from their mutual interaction, are also influenced by the needs for time distribution of the rights to use the same traffic areas by vehicles from different ways and directions, mutually intersecting. Apart from this, in the traffic of street and road networks, there are certain imbalances and uncertainty of traffic flow parameters. These imbalances are conditioned by the change of the intensity of traffic flows, so that in relation to the given variations and imbalances, different modes of traffic flow are defined. Vehicles of PT, especially buses in the situation where PT functions as a surface mode, operate in a mixed traffic flow; that is, they move with the other vehicles in traffic flow, sharing the same surface with them. For this reason, it can be rightfully assumed that the imbalance of traffic flow parameters influences the change of parameters of motion of all the vehicles, including the vehicles of PT. Understanding of unevenness and its impact on the variations of travel time of PT vehicles is important for modeling and transport simulation [7]. Knowledge of these changes and their influence on the functioning of PT vehicles enables better planning of work elements of PT vehicles, which would be in accordance with real traffic conditions. So far, there have been few research studies on variability of travel time of PT vehicles in mixed traffic flow [8]. For this reason, there is a need for carrying out further research in these conditions. When determining dynamic elements of PT vehicles' operation, the impact of the interaction between PT vehicles with other vehicles within mixed traffic flow is not considered. In this paper, a model for predicting travel time of PT vehicles has been developed; it will be using the data on basic traffic flow parameters, such as volume and speed of traffic flow. The developed model in this way considers unevenness of the real traffic flow when determining travel time of PT buses in mixed traffic flow. The real values of travel time enable more precisely defining the necessary number of PT vehicles for the purpose of keeping to the planned schedule. In this way, the main purpose of the paper has been fulfilled, that is, to define the mutual relationship of different traffic conditions and dynamic elements of PT vehicles operating, based on the determined rules of traffic flow parameters' change. Accordingly, it is possible to organize PT vehicles operating on the lines in mixed traffic flow, in accordance with traffic volume, that is, in accordance with the regime in which the traffic is performed. With this approach, the stability in the functioning of PT system can be achieved, and significant savings, as well as operating and external cost reduction, can be realized.

The paper is structured as follows: Section 2 contains literature review; Section 3 describes in detail how the model was developed; research area, research results, and model testing on a real line of PT in Novi Sad are presented in Section 4; Section 6 describes the savings and benefits that can be realized on the tested line, line number 4; in Section 7, conclusions and directions of further research are given.

\section{Literature Review}

Considering the fact that PT depends on traffic conditions, many researchers have studied interconnection of traffic flow parameters and elements of PT vehicle operation. Travel time is often observed as one of the elements which are significant for both passengers and the operator. Research studies imply that knowledge of the characteristics of traffic flow in real time is the condition for the increase of accuracy of the assessment of travel time [9]. Mori at al. [2] think that the approach based on the flow of traffic is very significant for predicting travel time. The assessment of travel time can be calculated based on data on vehicles in the network (flows, speeds, queues, density, etc.) [10]. Travel time varies during different time periods of the day, but also at different segments of the route used by public transport vehicles. The optimization model of bus travel time in a mixed traffic flow, developed by McKnight at al. [11], shows that each improvement of traffic flow functioning affects bus functioning as well. Increase of travel time of other vehicles in traffic flow is proportional to the increases of bus travel time. Pye and Bodé [12] showed by their model that volume, as one of the basic traffic flow parameters, has a significant influence on bus travel time. It is noticeable that volume occurs as a special parameter which influences capacity utilization in bus travel time models $[13,14]$. In the model developed by Fernandez and Valensia [13], delay parameter is used as a function of speed and road capacity. This model also comprises another basic traffic flow parameter, speed. Similarly, Tirachini and Hensher [15] developed a model for 
the calculation of cycle time where they analyzed bus subsystem. In the calculation of cycle time by their model, $\mathrm{v} / \mathrm{c}$ ratio and intersection delay, the conditions of the traffic flow of the observed lane, are taken into consideration. Tirachini et al. [16] proved the existence of the influence of traffic flow conditions on bus frequency. It was shown that bus frequency increases in a mixed traffic flow. Contrary to that, if buses have a special lane, that is, if they are separated from the mixed traffic flow, bus frequency decreases. Chepuri et al. [17] have researched travel time reliability for the chosen city bus routes, taking into consideration different traffic conditions and covering both spatial and time aspect. Generally, it can be concluded that PT vehicle in a mixed traffic flow interacts with other vehicles in the traffic flow. For that reason, PT vehicles in a mixed traffic flow face the problem of low service reliability and quality [18].

Apart from the influence of traffic flow conditions, the work elements are also affected by the characteristics of passenger flows in the very PT system itself. In their research, Ma et al. [9], apart from PT vehicles moving in traffic flow, also included bus dwell time. The aim of the research was to assess the travel time of the bus, based on the data in real time. The analysis included the route which is divided into segments; therefore, the motion of the bus along the route was observed independently of the dwell time. By dividing the route into segments, independent prediction models for the assessment of the running time and the dwell time were obtained. The research results imply that the travel time of the bus is more precisely predicted if based on the model with segments. Buchel and Corman [7] also studied travel time and its variabilities. They observed the travel time of the bus as a sum of dwell time and running time. Thus, running time includes the time in motion and dwell time caused by signalization and other traffic conditions along the route. Zhou at al. [19] consider the information on passengers boarding, a significant factor which affects the travel time. Different studies connected travel time to different distributions, such as normal distribution, log-normal distribution, gamma distribution, logistic distribution, and loglogistic distribution [8].

Considering the fact that, due to the imbalances of passenger flows, the vehicles' dwell time is variable and the conditions of vehicles' moving along the route are different, which additionally affects travel time of PT vehicles, especially in interrupted traffic flow conditions, that kind of vehicle flow is very difficult to mathematically define. Therefore, it is started from an approximation that vehicles go along the whole route evenly, wherefore the timetable is designed with predefined, unchangeable operating elements for typical periods in a day. The data used in the calculations of operating elements of PT vehicles are exclusively related to this system. Thus, input data for the timetable design are the characteristics of the routes of regular public transport of PT, the timetable of other bus lines for enabling changes at certain change points, the characteristics of PT vehicles, the passenger flows, etc. [20]. The characteristics of passenger flows, in certain time periods in a day, are known in advance, and the influence of their stochasticity is compensated for through the coefficient of utilization of capacity on the most burdened section of the line and the factors of uneven passenger flow. On the other hand, when a timetable and, therefore, the operating elements of the vehicles of PT surface modes are designed, stochasticity of traffic flows is not analyzed in any way, and thus their influences on the functioning of PT vehicles are not considered.

Literature overview implies that all these developed models of travel time are most often tested by simulation, applying certain software packages. Thus, for the needs of simulation, different research scenarios are predefined. Therefore, it can be concluded that testing is carried out in partially controlled conditions, which can significantly deviate from real conditions. The model developed in this paper was tested for real traffic conditions. The model testing in real conditions enables the comparative analysis of the values obtained in real research studies, which implies in a most complete way the quality of the model itself. Generally, it can be concluded that, regardless of the way the models were tested, all researchers came to the unique conclusion that traffic conditions have a significant impact on the travel time of PT vehicles. Capacity utilization is a parameter that is most often used as input data in travel time modeling.

\section{Methodology}

In this paper a travel time optimization model has been developed for the vehicles of surface transit modes running on road; apart from common parameters, the model comprises uneven traffic flow parameters (Figure 1). The travel time of PT vehicles from the starting to the last point has been chosen for the reason that, through the intensity of this value, the influence of traffic flow conditions on the street network can be best perceived. The flow and the speed of traffic flow, being traffic flow parameters, have been taken as input values into the model, because, along with the density, they are the most important traffic flow parameters. Furthermore, these two values are easily measurable in real conditions.

Travel time is a value which is directly dependent on the transport speed achieved on the line, so that it is

$$
T_{T}=\frac{2 L}{V_{T}} 60[\mathrm{~min}],
$$

where $L$ is the line length $[\mathrm{km}]$ and $V_{T}$ is the travel speed $[\mathrm{km} / \mathrm{h}]$.

So far, in practice in towns of Serbia and wider surrounding countries, when a timetable is designed, the travel speed is taken as a constant value for each line separately, and in most cases it is constant during the whole working time of the vehicle on the line. Only occasionally do operators take into consideration the average travel time by the segments of street network between the intersections. Stochasticity of traffic flows has been neither analyzed in any way nor considered as influential regarding PT vehicles. Marković et al. [21] in their paper considered stochasticity when solving the vehicle routing problem with stochastic demands. Since the road vehicles of PT move in a mixed traffic flow, they represent a part of that flow, and their movement is conditioned by the movement of the entire 


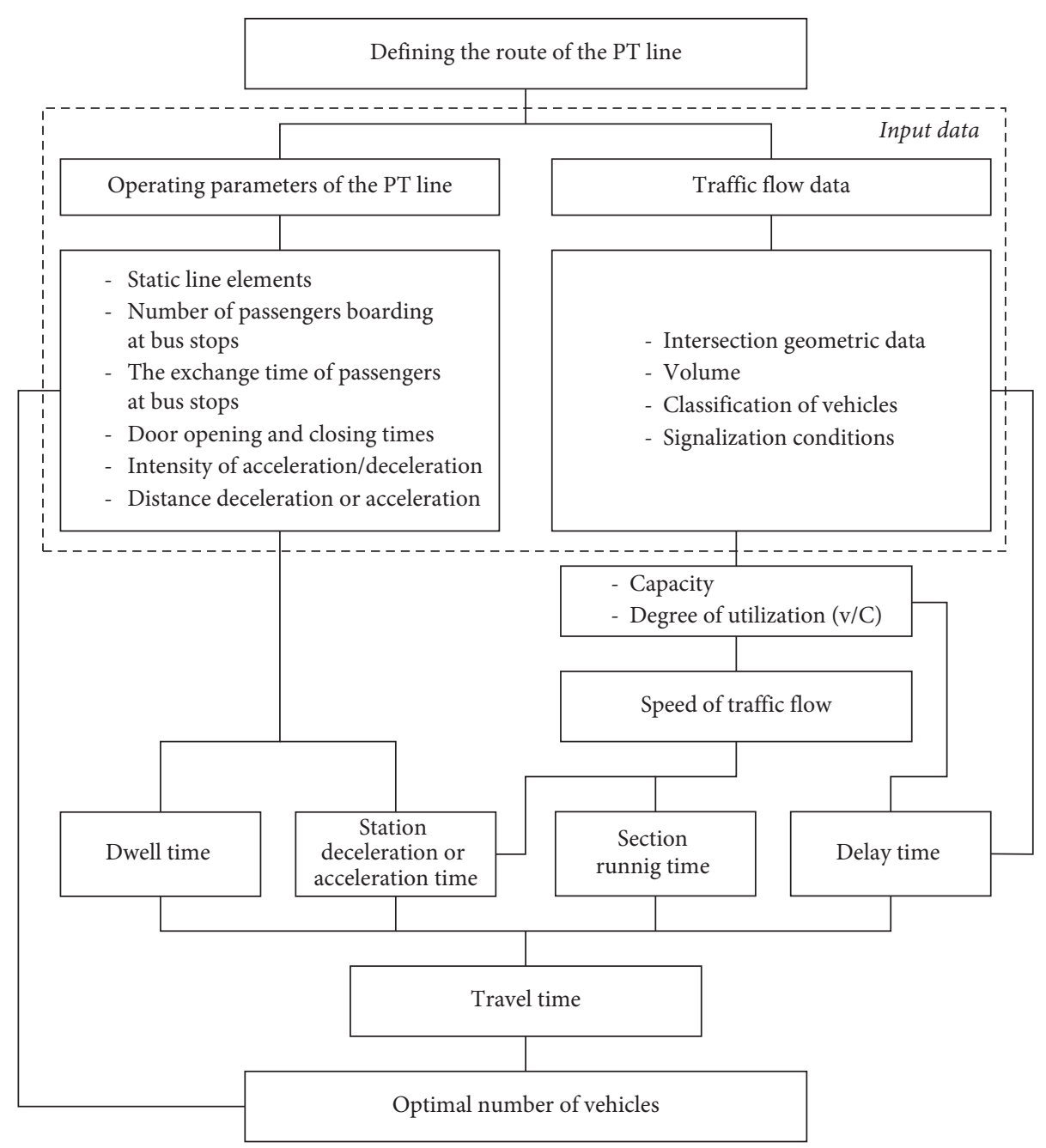

FIgURE 1: Diagram flow of the model methodology.

traffic flow. For this reason, it is necessary to highlight the fact that traffic flow speed, including the speed of PT vehicles in a mixed traffic flow, cannot be observed as a fixed value, but it is a direct function of the traffic conditions on the observed route. The speed of traffic flow depends on the relation of the flow and the capacity, the number of intersections the flow goes through, the type of the maneuvers the vehicles perform at an intersection, the type of traffic regulation, and others. Therefore, in the conditions of occasionally interrupted traffic flow, there are certain delays which decrease the average travel speed, that is, increase the realized travel time. Other researchers also determined that travel time is affected, among other factors, by traffic flow, passengers boarding and alighting, traffic signalization $[22,23]$. PT vehicles have additional delays gained during each dwell time. Apart from waiting for the exchange of passengers at a bus stop, PT vehicles have to, just before stopping, decelerate their movement; that is, when joining traffic flow, they have to accelerate their movement to reach the speed of traffic flow. Bearing this in mind, as well as the previously stated relations, it is possible to express the travel speed of PT vehicles as the function of the following variables:

$$
V_{T}=f\left(t_{r}, t_{s}, t_{b}, t_{a}, d\right),
$$

where $t_{r}$ is the running time, $t_{s}$ is the dwell time on stops, $t_{b}$ is the deceleration time for stopping at the bus stop, $t_{a}$ is the acceleration time for joining the traffic flow, and $d$ is the delay.

Consequently, the travel time can be expressed as a function of the same variables; that is,

$$
T_{T}=f\left(t_{r}, t_{s}, t_{b}, t_{a}, d\right) .
$$

The running time of a vehicle on a section is directly dependent on the length of the observed section and the speed on the section. Therefore, it can be stated in the following relation:

$$
t_{r}=\frac{L}{V} \cdot 60[\mathrm{~min}],
$$

where $\mathrm{V}$ is the speed of traffic flow $[\mathrm{km} / \mathrm{h}]$.

Approaches to determining travel time based on the theory of traffic flow use different theoretic macroscopic and microscopic models. The main advantage of these approaches is that, in that way, there is an insight into the total traffic situation in the street network [24]. 
In the theory of traffic flow, different models have been developed showing the connection between the speed and density or the flow of traffic. Since the flow is the easiest measurable value, in this paper, the traffic flow speed is stated through the flow.

Numerous professional literature works which process issues related to mutual relations between the speed and the flow of vehicles show that there is not a unique model between these two values which is applicable in the conditions of occasionally interrupted traffic flows, but the connections between them can be observed as idealized, theoretic, and practical, obtained by measurement in real conditions (thus, the established relation is valid only for those specific conditions) and in simulations [25-28].

For the needs of the model, the recommendations have been adopted for establishing the relations between the speed and the flow, through the capacity utilization, for city streets, depending on the type of the city street and the number of signals which occur by a kilometer of the observed intersection, given in [29] (Figure 2).

On the basis of the diagram in Figure 2, it is possible to establish the legitimacy of the speed change depending on the capacity utilization. Legitimacy of speed change depending on the capacity utilization was established by applying regression analysis. It was established that the dependence of these two values is well described by a thirddegree polynomial curve, which is also shown by the obtained correlation coefficient of 0.99. Thus, Figure 3 shows the legitimacy of the change of these values, which differ depending on the number of the signalized intersections by a kilometer of the route.

Considering the fact that the capacity utilization represents the relation between the flow and the capacity, consequently, it is related to the speed of traffic flow and the flow and therefore to travel time of PT vehicles.

3.1. Dwell Time. During their movement on the route, PT vehicles stop at the stops for the exchange of passengers, and the following actions are done:

(i) Deceleration to stop at the bus stop

(ii) Opening of the vehicle's door

(iii) Exchange of passengers (entries and exits)

(iv) Closing the vehicle's door

(v) Acceleration of the vehicle after leaving the bus

Each of the stated actions demands certain time; therefore, the dwell time, in accordance with the stated actions, can be written as

$$
t_{s}=\left(t_{b}+t_{o d}+t_{A B}+t_{c d}+t_{a}\right) \cdot \frac{1}{60}[\mathrm{~min}],
$$

where $t_{o d}, t_{c d}$ are the door opening and closing times [s] (note: they represent constants which are adopted depending on the technical characteristics of the vehicle) and $t_{A B}$ is the time necessary for the alighting and boarding of passengers [s].
Apart from the elements previously stated, the frequency of buses along a route is also important, as well as the capacity of a bus stop, because at the stops with a higher frequency there is often waiting time to approach the bus stop; therefore, sometimes, there is a queue. Sometimes, it can also happen that vehicles at the bus stop block the movement of the vehicles which are about to leave the stop, because they have finished the process of passenger exchange earlier. When a vehicle from a bus stop is about to join the traffic flow, it can be hindered by the motion of the other vehicles in the traffic flow; thus, it also affects the increase of the waiting time at a stop. When the model was designed, a limitation was made in the sense that there is an assumption that there is not a queue to the access of the bus stop for the vehicles of PT; that is, each vehicle of PT regularly approaches the stop where the exchange of passengers is done, and after that, without any obstructions, joining traffic flow is performed.

The time necessary for the passengers' time boarding and alighting is affected by the following factors:

(i) The number of passengers boarding and alighting

(ii) Technical characteristics of the vehicle (the number of doors, the width of the door, the height of the vehicle's floor, and the width of the transit space in the vehicle)

(iii) The mode of passengers' exchange (the exchange at all doors, entry only at the front door, and exits at all other doors)

(iv) Charging and fare system

Depending on the previously stated elements, different variations of calculations of passenger exchange time can be done. Everything is affected by the factors which will be included in the calculation (number of doors in the vehicle; number of simultaneous passenger entries into the vehicle; type of vehicle, that is, a low-floor vehicle or vehicle with stairs; and other).

After an overview of the literature related to the vehicles waiting at bus stops, it is possible to make a general conclusion that the waiting is greatly affected by the applied charging system and that the dwell time is the direct function of the number of passengers which approach the system, that is, enter the vehicles of PT. The time taken by passengers to alight is significantly shorter than that taken to board, so that research studies are usually based on passengers boarding $[15,30-34]$.

In Novi Sad, the bus subsystem with classical charging system is applied, where the charging and the control of monthly passes are done by the driver. During the process of passenger exchange, getting on the vehicle is done at the front door and getting off at all other doors. This charging system is considered to be the slowest, and, according to the research studies carried out in Novi Sad, the average time necessary for passengers' entries, on the level of the whole system, is $4.2 \mathrm{~s}$ /passenger [35].

Considering what was previously stated, the exchange time of passengers at bus stops in the model for the bus 


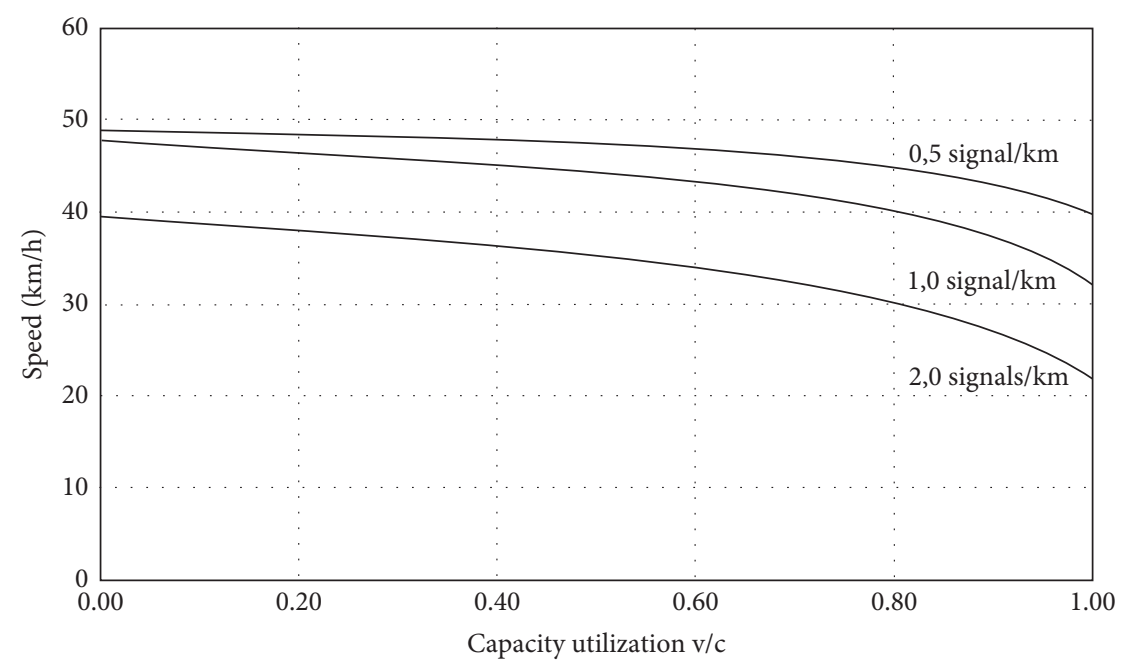

FIgURE 2: Speed-flow curves for the class II urban street [29].

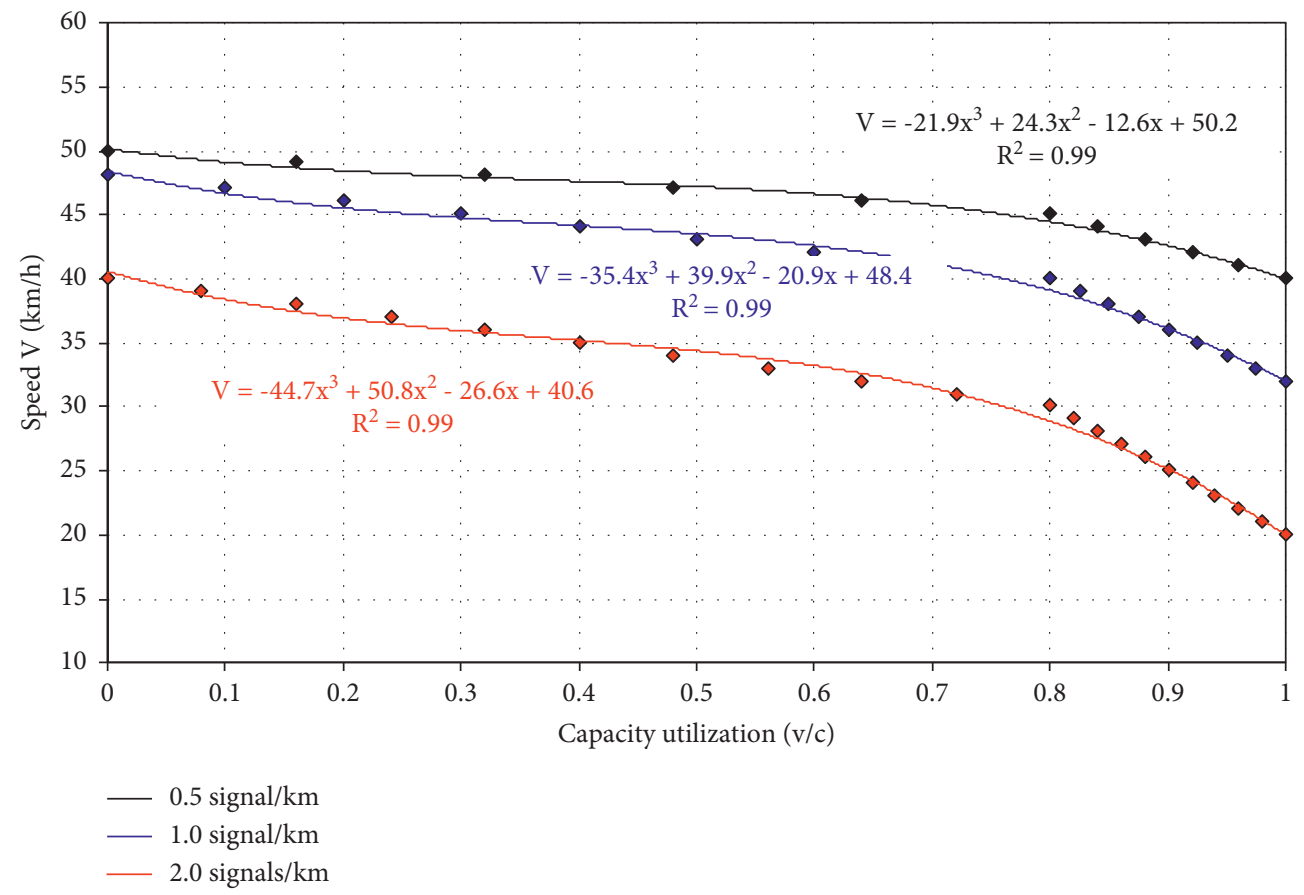

FIGURE 3: Legitimacy of the traffic flow speed change depending on the capacity utilization and the number of signalized intersections by a kilometer of the route.

subsystem of PT in Novi Sad can be calculated by the following equation:

$$
t_{A B}=\frac{4.2 \cdot \mathrm{NP}_{b}}{60}[\mathrm{~min}],
$$

where $\mathrm{NP}_{b}$ is the number of passengers boarding [pas/h].

3.2. Deceleration Time and Acceleration Time of the Vehicle. Deceleration and acceleration time of PT vehicles are in the function of the speed of the vehicle and the values of the realized deceleration, that is, acceleration of the vehicle. In the professional literature, there are recommendations for the values of comfortable acceleration and deceleration of the bus from the viewpoints of passengers within the limits $1-1.8 \mathrm{~m} / \mathrm{s}^{2}$ [36]. For the needs of the model making, the same value was taken for the intensity of acceleration/deceleration, which is $1.5 \mathrm{~m} / \mathrm{s}^{2}$.

The model account has been taken of the distance that vehicles cross during deceleration or acceleration.

3.3. Delay. On the route of the observed PT line, there are a significant number of intersections, so that in that case their influence on the overall travel time is significant. Delay $(d)$ at signalized and priority intersections in the model were 
calculated by the methodology described in [29]. Khadhir et al. [37] in their paper researched delay estimation at signalized intersections for mixed traffic conditions. By applying the methodology for the calculation of delays described in their paper, they obtained, with an additional calibration, satisfactory results for mixed traffic conditions, which are researched in this paper.
3.4. Model. After defining all individual segments, which are significant for the calculation of travel time of the road vehicles of $\mathrm{PT}$, this value will be calculated according to the defined model as

$$
T_{T}=\left(\sum_{i=1}^{n s}\left(\frac{L-2 \cdot S}{V}\right)_{i}+\sum_{i=1}^{n b s}\left(\frac{2 \cdot V}{b}\right)_{i}+\sum_{i=1}^{n b s}\left(\frac{t_{o d}+t_{A B}+t_{c d}}{3600}\right)_{i}\right) \cdot 60+\sum_{i=1}^{n s i g} d_{i}+\sum_{i=1}^{n p r} d_{i}[\min ] .
$$

That is, for the area of Novi Sad,

$$
T_{T}=\left(\sum_{i=1}^{n s}\left(\frac{L-2 \cdot S}{V}\right)_{i}+\sum_{i=1}^{n b s}\left(\frac{2 \cdot V}{b}\right)_{i}+\sum_{i=1}^{n b s}\left(\frac{t_{o d}+4.2 \cdot N P_{b}+t_{c d}}{3600}\right)_{i}\right) \cdot 60+\sum_{i=1}^{n s i g} d_{i}+\sum_{i=1}^{n p r} d_{i}[\min ],
$$

where $n s$ is the number of sections on the observed line, $n b s$ is the number of bus stops, nsig is the number of signalized intersections, and $n p r$ is the number of priority intersections.

The traffic flow speed $(V)$ for the territory of Novi Sad is possible to calculate by legitimacy 3 (Figure 3 ) on the route of line 4; on average, there are two signals by a kilometer of the route.

$$
V=-44.7 \cdot\left(\frac{v}{c}\right)^{3}+50.8 \cdot\left(\frac{v}{c}\right)^{2}-26.6 \cdot\left(\frac{v}{c}\right)+40.6 .
$$

In order to obtain the model, which is really applicable in practice and comparable to the research results in real work conditions, the data were observed within the interval of one hour. This generalization was done because the movement of individual vehicles in the flow cannot be considered valid for making general conclusions.

\section{Model Testing Results}

The developed model will be tested on real data obtained in the research, while each component which influences the travel time of the vehicle, from the starting to the end point, will be determined individually:

\section{(i) Running time \\ (ii) Dwell time \\ (iii) Delay}

The obtained data will be compared with the measured values of the travel time of PT vehicles, and, based on the comparative analysis, it will be possible to check the developed model, that is, to test the possibility of its practical change.

For the model testing, bus line number 4 of PT in Novi Sad was chosen, whereby the influence of traffic flow measured parameters on the functioning of that line was studied. The choice of this line for the analysis was conditioned by its route stretching in the city street network, because it was necessary for the analysis to select those roads, as well as PT lines on the territory of Novi Sad which are sufficiently representative from the aspect of characteristics which define them. Virtually, the choice of PT line that is going to be studied at the same time is the choice of the road where the characteristics of traffic flow are going to be studied and vice versa.

The data necessary for the testing were taken from the research of the system of public transport and the research of traffic flow characteristics, carried out on the territory of Novi Sad for the needs of creating a transport model of Novi Sad [38].

4.1. Research Studies. Research studies about the system of public transport were carried out with the aim of creating initial, reliable, and comprehensive information base about the market of transport services, for the needs of strategic and operational management of the system of public transport of passengers in Novi Sad. For the needs of counting, 1,200 counters were engaged, distributed in the vehicles, by a predefined schedule. For each of the existing lines, there were prepared forms for counting with a code and the name of the bus stop, taken from the distance map of the city transport company. The placement of the counters was done by the garage numbers of the vehicles, for each line, in accordance with the work timetable of the dispatching office. The counters recorded passengers boarding and alighting, as well as the pass time of vehicles through each bus stop.

In order to develop the transport model, counting and analysis of the characteristics of traffic flow at 61 intersections on the city territory were carried out. Traffic counting was done continually during the whole day, in the period 06: 00-22:00 $\mathrm{h}$, in 15-minute intervals, according to the structure of the traffic flow. 
4.2. Research Area. Bus line number 4 partly operates in Bulevar oslobođenja, which could be said to be one of the most significant and busiest streets in Novi Sad. It goes through the very center of the city, and the last part of this line goes through Narodnog fronta, a street which is on the eastern edge of Novi Sad and also represents one of the busiest streets in terms of traffic.

The route of line 4 was divided into this analysis into sections, so that one section stretches between two intersections. On the route of line 4 , there are 16 intersections, out of which 14 are regulated with traffic lights and 2 are regulated with priority signs (Figure 4). Considering the number of intersections on line 4, 15 sections of the route were analyzed (Figure 4).

Since most of the analyzed intersections are regulated by traffic lights, it was necessary to acquire timing plans and work schedules for the traffic lights in the period of research. Work schedules, timing plans, and disposition of light signals were obtained from the Institute for City Construction and Development Novi Sad (SAUS center).

The total length of the line is $11,150 \mathrm{~m}$, whereby the length of the line in direction A is $5,500 \mathrm{~m}$ and in direction B is $5,650 \mathrm{~m}$. Since the route of the line is the same in both directions, the distance difference of 150 meters occurs due to the position of terminus on the line, that is, due to the initial point and the end of the travel on the bus route. Terminuses of line 4 are at the station and in Liman IV, that is, at the intersection of streets Narodnog fronta and Ive Andrića.

Movement from Liman IV towards the station was marked as direction A, while the opposite movement, that is, the movement from the station towards Liman IV was marked as direction B. Along the route of line 4, there are 12 stops in each direction. All stops were determined by their code and the bus stop name, and in Tables 1 and 2, apart from these two pieces of data, the distance between stops and the route length were also shown for direction $\mathrm{A}$ and direction $\mathrm{B}$, respectively.

4.3. Research Results. This section presents the parts of the research necessary for the calculation of travel time of PT vehicles by the developed model.

The designed scheduled round trip time for line 4 is 60 minutes; that is, the time of the half-cycle in direction $\mathrm{A}$ is equal to the half-cycle time in direction $\mathrm{B}$ and it is 30 minutes. Therefore, by the designed conditions, the cycle time was taken as a constant value, regardless of the work period of a vehicle. The terminal time consists of the travel time and the terminal (reversing) time, whereby it was predicted that the terminal time lasts for 5 minutes for each terminus. Thus, the travel time planned by the timetable lasts for 25 minutes in each direction. During the research in a real system, travel time was measured, from the bus departure from the first stop to the arrival at the last stop, and the obtained results for each of the 104 observed departures are shown in Figures 5 and 6.

After analyzing the results of the research, it is possible to conclude that realized values of the travel time of the vehicles on PT line 4 are, to a significantly greater or lesser extent, different from the designed scheduled values. The diagrams in Figures 7 and 8 show the hour values of travel time of line 4 buses, for the reason that hour values are used in the calculation in the model.

As it has been stated before, passengers' boarding of the bus is necessary for the calculation of the vehicles waiting time at bus stops. Therefore, its values, observed by hour distribution, for each bus stop, are shown in Tables 3 and 4, for direction $\mathrm{A}$ and direction $\mathrm{B}$, respectively.

Since it necessary to know the utilization of capacity for the calculation of traffic flow speed, the measured flow was related to the capacity of each individual section. Therefore, Tables 5 and 6 show the values of capacity utilization for each observed section along the route of bus line 4, for both directions, direction A (Table 5) and direction $\mathrm{B}$ (Table 6).

4.4. Testing Results. In the research, measurement started from the moment of a vehicle's movement from the first bus stop; therefore, when the model was designed, it was taken into account that the first stop's waiting time is not calculated. Moreover, for the first stop, observed in direction A, the deceleration time for stopping at the bus stop was not calculated, but only the acceleration time of the vehicle to reach the traffic flow speed was calculated. On the first section, observed in direction $\mathrm{B}$, virtually, there is not a stop, since it is immediately before the intersection of two boulevards, Bulevar Jaše Tomića and Bulevar oslobođenja, so this stop does not have the calculations of either deceleration or acceleration.

According to the derived legitimacy 8, traffic flow speed can be expressed through the capacity utilization, that is, through the flow and the capacity of sections. The established legitimacy is valid for the degree of utilization from 0 to 1 . In real conditions, there are often situations when the flow demands exceed the capacity; therefore, during the model testing, the following limitation was made: in case the capacity utilization is bigger than 1 , the value 1 is adopted. The model testing was done for the period $06.00-22.00 \mathrm{~h}$, and the results of the model testing are shown in Tables 7 and 8 .

Values of travel time obtained in the model deviate from the realized values of travel time, but it can be stated that generally there are not any significant deviations (Figures 9 and 10). The exception is the difference in these values, obtained for direction $\mathrm{A}$, in the morning period 06.00-7.00 o'clock, where the deviation of the model values in relation to the real values is 4.5 minutes (Figure 9). The value of the travel time of 16.5 minutes, obtained in the period 6.00-7.00 o'clock, for direction A, is certainly not unreal, since it was previously determined, based on the research results, that certain departures in a day were made even with lower values of traveling time. One of the factors which can significantly affect the realized values of travel time is the human factor, that is, the influence of PT vehicle's driver himself on the mode and the speed of his driving, which was not considered in this paper. 


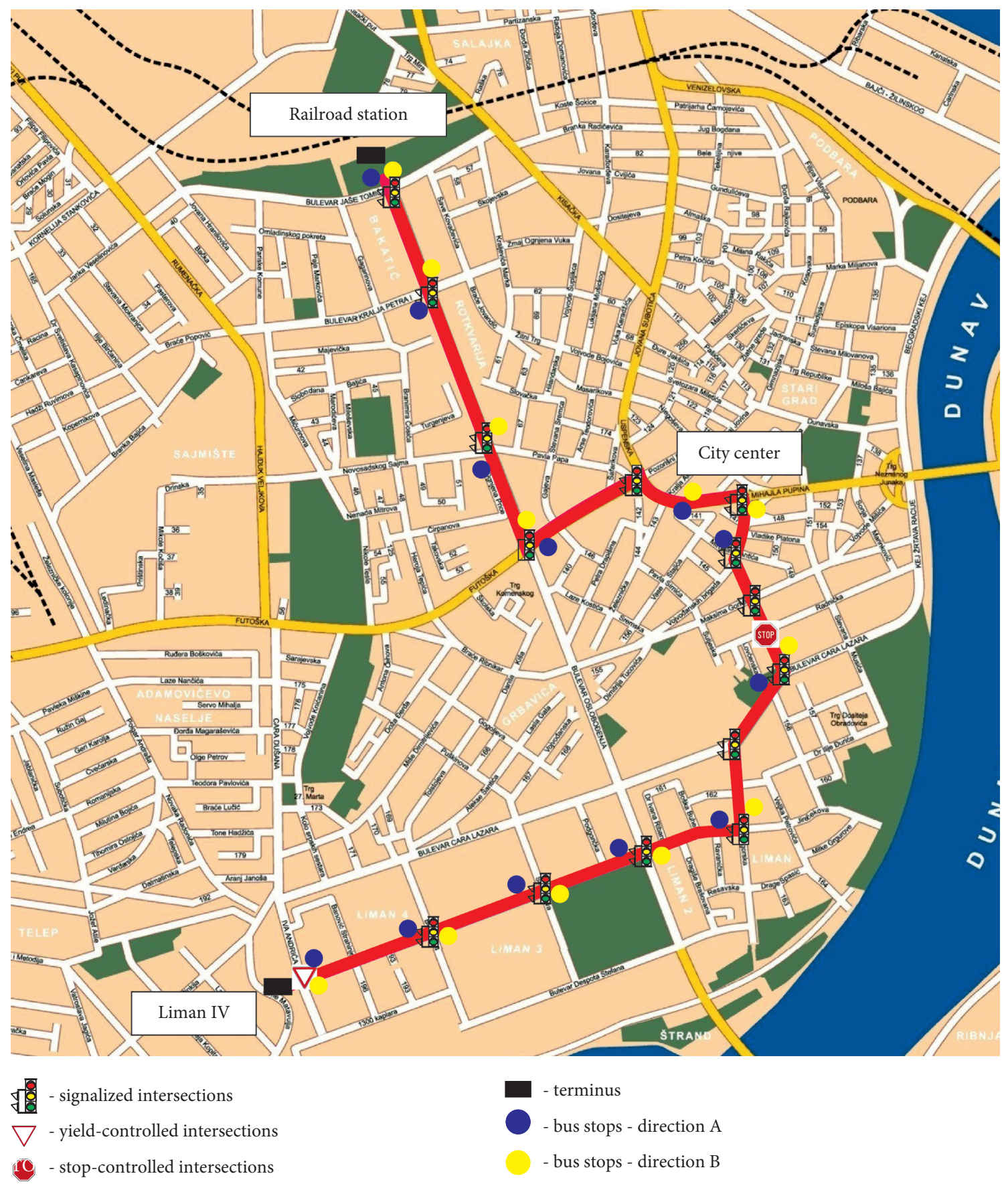

Figure 4: Horizontal view of the line 4 route.

Evaluating the differences between the modeled values of travel time of PT vehicles and the values of travel time of $\mathrm{PT}$ values determined in the research in real traffic flow can be achieved through the following measures: root mean squared normalized error (RMSN), correlation coefficient (CC) and mean absolute percentage error (MAPE) [39].

Table 9 shows the deviation values of results of travel time of PT vehicles obtained by simulation from the real values of travel time of PT vehicles, obtained through three previously described statistical measurements.
Each of the three applied statistical measures showed that there has been concurrence of the simulated results of $\mathrm{PT}$ vehicles traveling time and the results of PT vehicles traveling time obtained in the research; that is, the deviations between these values are within the acceptable limits.

\section{Model Application}

The work on PT lines is organized by certain typical periods. There are different research studies dedicated to the quantification of time variations of travel time [40-42]. 
TABle 1: Characteristics of the stops of line 4, direction A.

\begin{tabular}{lcccc}
\hline & & \multicolumn{2}{c}{ Line number 4: Liman IV-center-railroad station (direction A) } \\
No. & Bus stop code & Bus stop name & Distance between stops (m) & Route length (m) \\
\hline 1 & 0414B & Narodnog fronta-Ive Andrića & 0 & 0 \\
2 & 0415B & Narodnog fronta-Balzakova & 500 & 500 \\
3 & 0416B & Narodnog fronta-Šekspirova & 400 & 1000 \\
4 & 0417B & Narodnog fronta-Bul. oslobođenja & 400 & 1400 \\
5 & 0418B & Fruškogorska-Dr Ilije Đuričića & 600 & 2400 \\
6 & 0419B & Stražilovska-Urbis & 400 & 2800 \\
7 & 0420B & Žarka Zrenjanina-Izvršno veće & 400 & 3200 \\
8 & 0620B & Bulevar Mihajla Pupina-RK Bazar & 700 & 3900 \\
9 & 0536B & Bulevar oslobođenja-Futoška pijaca & 400 & 700 \\
10 & 0537B & Bulevar oslobođenja-Pokrajinski SUP & 500 & 5000 \\
11 & 0538B & Bulevar oslobođenja-Kokra & & 5500 \\
12 & 0507AT3 & Railroad station & & \\
\hline
\end{tabular}

TABLE 2: Characteristics of the stops of line 4, direction B.

\begin{tabular}{lcccc}
\hline & & \multicolumn{2}{c}{ Line number 4: railroad station-center-Liman IV (direction B) } \\
No. & Bus stop code & Bus stop name & Distance between stops $(\mathrm{m})$ & Route length $(\mathrm{m})$ \\
\hline 1 & 0507AT3 & Railroad station & 0 & 0 \\
2 & 0509A & Bul. oslobođenja-Lutrija Vojvodine & 500 & 500 \\
3 & 0510A & Bul. oslob.-Novosadskog sajma & 400 & 1200 \\
4 & 0337B & Jevrejska-Futoška pijaca & 600 & 1600 \\
5 & 0601A & Bulevar Mihajla Pupina-underpass & 350 & 2200 \\
6 & 0401A & Žarka Zrenjanina-municipality & 540 & 3090 \\
7 & 0402A & Bulevar Cara Lazara-URBIS & 660 & 3750 \\
8 & 0403A & Fruškogorska-Jirečekova & 500 & 4250 \\
9 & 0404A & Narodnog fronta-Bul. oslobođenja & 400 & 460 \\
10 & 0405A & Narodnog fronta-Šekspirova & 450 & 5100 \\
11 & 0406A & Narodnog fronta-Balzakova & 550 & 5650 \\
12 & 0408OK & Narodnog fronta-Ive Andrića & &
\end{tabular}

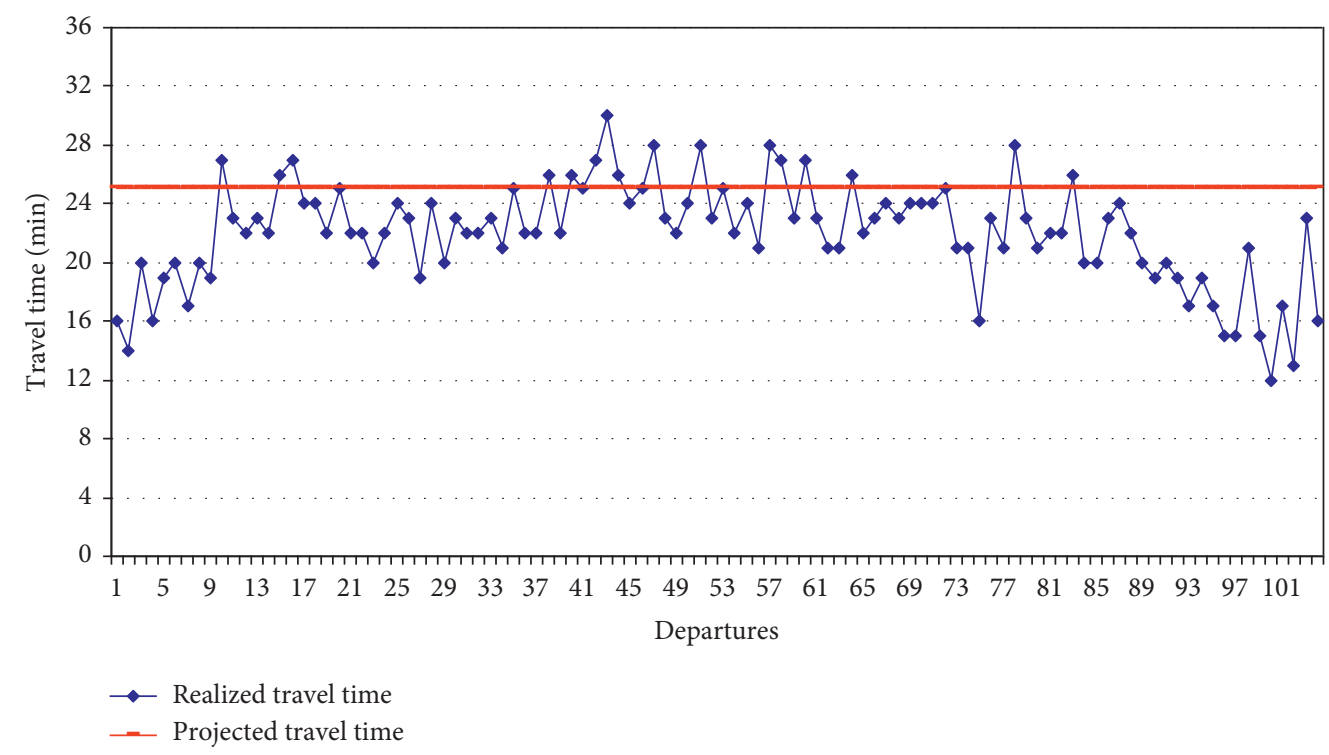

Figure 5: Travel time by individual departures from direction A.

Variations of travel time can be observed within the same period or between different periods within the same day $[22,43,44]$. For the analysis, it would be ideal to identify certain time periods in which the applied managing strategies can most affect the reliability of travel time [45]. Time periods are determined by the activities of the residents of a 


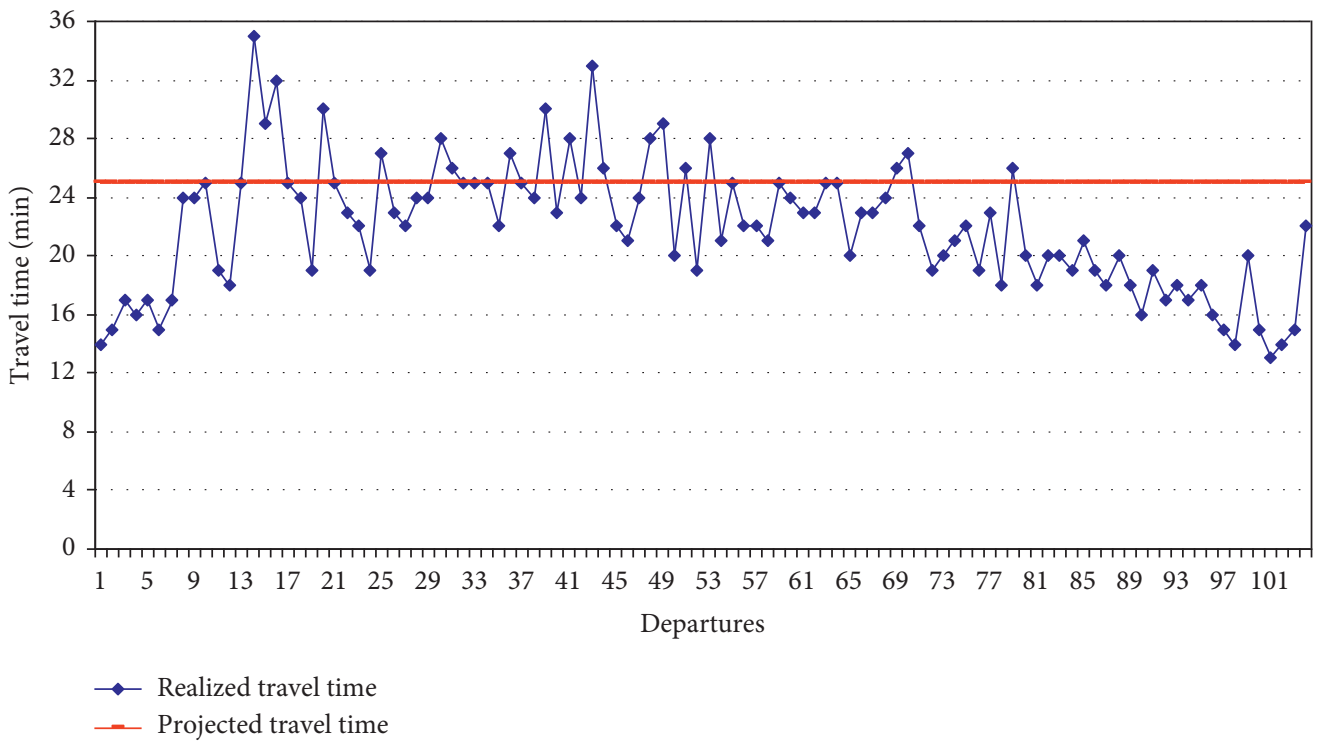

FIgURE 6: Travel time by individual departures from direction B.

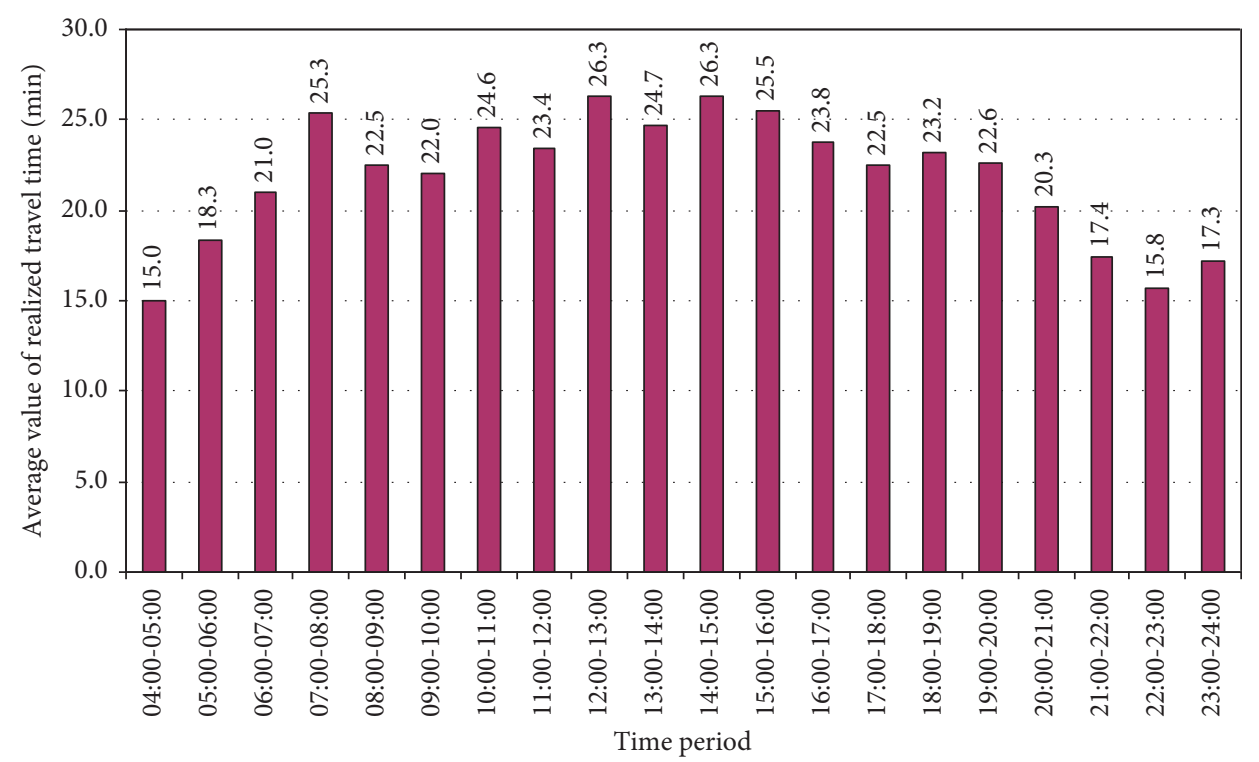

Figure 7: Average value of travel time, by hours in a day, observed in direction A.

certain area, that is, their transport demands. In literature [46], it is recommended that six typical daily periods are separated, including peak volumes, off-peak volumes, early morning period, and evening period, which lasts to the end of vehicle's operating on lines (Figure 11). Time distribution by periods in which the same number of vehicles operate, apart from being harmonized with the demands for transport, is, to a certain degree, limited by the very organization of public transport system.

The data obtained through the developed model also imply the existence of the previously described typical periods, for which there is a calculation in Table 10 regarding the number of vehicles operating for a fixed adopted time of the cycle on the line lasting for 60 minutes and the time obtained in the model considering the same headway.
Dependence of the number of vehicles on the adopted value of cycle time, as well as the planned headway, can be best seen in Figure 12.

On the lines of public transport with the largest number of vehicles, it is very important to maintain the planned headway. The model has shown that it is possible to achieve certain savings regarding the number of vehicles with the unchanged headway, that is, the unchanged level of service which is offered to the users.

Comparative analysis of the obtained results implies the conclusion that, by considering the influence of the change of traffic flow parameters in mixed traffic flow condition in 4 out of 6 operating periods, savings can be achieved in the way that one vehicle fewer will be operating by a line. In accordance with the change of the typical operating periods 


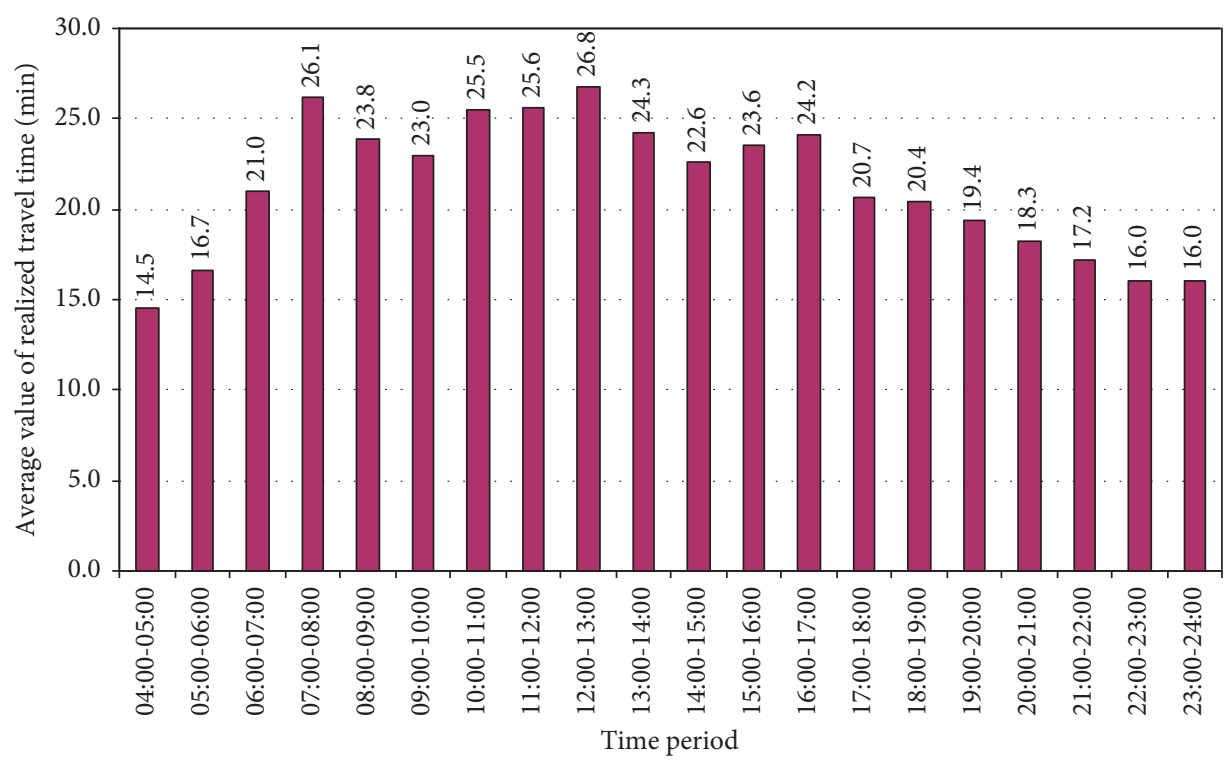

Figure 8: Average value of travel time, by hours in a day, observed in direction B.

TABle 3: Hour distribution of entries by bus stops, observed in direction A.

\begin{tabular}{|c|c|c|c|c|c|c|c|c|c|c|c|c|c|c|c|c|}
\hline $\begin{array}{l}\text { Number } \\
\text { of bus } \\
\text { stop }\end{array}$ & $\begin{array}{c}06.00- \\
07.00\end{array}$ & $\begin{array}{c}07.00- \\
08.00\end{array}$ & $\begin{array}{c}08.00- \\
09.00\end{array}$ & $\begin{array}{c}09.00- \\
10.00\end{array}$ & $\begin{array}{c}10.00- \\
11.00\end{array}$ & $\begin{array}{c}11.00- \\
12.00\end{array}$ & $\begin{array}{c}12.00- \\
13.00\end{array}$ & $\begin{array}{c}13.00- \\
14.00 \\
\text { Direct } \\
\end{array}$ & $\begin{array}{c}14.00- \\
15.00 \\
\text { tion A } \\
\end{array}$ & $\begin{array}{r}15.00- \\
16.00\end{array}$ & $\begin{array}{c}16.00- \\
17.00\end{array}$ & $\begin{array}{c}17.00- \\
18.00\end{array}$ & $\begin{array}{c}18.00- \\
19.00\end{array}$ & $\begin{array}{c}19.00- \\
20.00\end{array}$ & $\begin{array}{c}20.00- \\
21.00\end{array}$ & $\begin{array}{r}21.00 \\
22.00\end{array}$ \\
\hline 1 & 37 & 110 & 79 & 39 & 55 & 31 & 50 & 78 & 78 & 39 & 55 & 43 & 21 & 37 & 28 & 12 \\
\hline 2 & 54 & 138 & 121 & 65 & 61 & 73 & 66 & 91 & 72 & 62 & 48 & 48 & 51 & 40 & 25 & 21 \\
\hline 3 & 27 & 90 & 75 & 33 & 48 & 30 & 50 & 57 & 52 & 48 & 49 & 24 & 34 & 32 & 18 & 17 \\
\hline 4 & 17 & 60 & 29 & 10 & 23 & 21 & 33 & 44 & 34 & 20 & 28 & 10 & 15 & 14 & 6 & 4 \\
\hline 5 & 20 & 41 & 51 & 22 & 43 & 39 & 55 & 41 & 60 & 53 & 49 & 50 & 44 & 22 & 31 & 13 \\
\hline 6 & 2 & 13 & 48 & 89 & 155 & 124 & 262 & 226 & 194 & 214 & 196 & 185 & 159 & 71 & 118 & 20 \\
\hline 7 & 6 & 17 & 18 & 13 & 22 & 26 & 27 & 38 & 61 & 57 & 38 & 16 & 30 & 41 & 25 & 5 \\
\hline 8 & 23 & 35 & 37 & 42 & 76 & 75 & 114 & 98 & 86 & 105 & 76 & 43 & 95 & 81 & 57 & 30 \\
\hline 9 & 13 & 30 & 23 & 37 & 65 & 42 & 64 & 85 & 52 & 82 & 68 & 21 & 79 & 46 & 7 & 15 \\
\hline 10 & 3 & 9 & 6 & 7 & 7 & 11 & 20 & 31 & 14 & 21 & 9 & 11 & 21 & 4 & 5 & 2 \\
\hline 11 & 0 & 4 & 2 & 6 & 5 & 7 & 5 & 19 & 15 & 15 & 1 & 0 & 7 & 4 & 2 & 3 \\
\hline 12 & 0 & 0 & 0 & 0 & 0 & 0 & 0 & 0 & 0 & 0 & 0 & 0 & 0 & 0 & 0 & 0 \\
\hline
\end{tabular}

TABLE 4: Hour distribution of entries by bus stops, observed in direction B.

\begin{tabular}{|c|c|c|c|c|c|c|c|c|c|c|c|c|c|c|c|c|}
\hline $\begin{array}{l}\text { Number } \\
\text { of bus } \\
\text { stop }\end{array}$ & $\begin{array}{c}06.00- \\
07.00\end{array}$ & $\begin{array}{c}07.00- \\
08.00\end{array}$ & $\begin{array}{c}08.00- \\
09.00\end{array}$ & $\begin{array}{c}09.00- \\
10.00\end{array}$ & $\begin{array}{c}10.00- \\
11.00\end{array}$ & $\begin{array}{c}11.00- \\
12.00\end{array}$ & $\begin{array}{c}12.00- \\
13.00\end{array}$ & $\begin{array}{c}13.00- \\
14.00 \\
\text { Direct }\end{array}$ & $\begin{array}{c}14.00- \\
15.00 \\
\text { ion B }\end{array}$ & $\begin{array}{c}15.00- \\
16.00\end{array}$ & $\begin{array}{c}16.00- \\
17.00\end{array}$ & $\begin{array}{c}17.00- \\
18.00\end{array}$ & $\begin{array}{c}18.00- \\
19.00\end{array}$ & $\begin{array}{c}19.00- \\
20.00\end{array}$ & $\begin{array}{c}20.00- \\
21.00\end{array}$ & $\begin{array}{c}21.00- \\
22.00\end{array}$ \\
\hline 1 & 219 & 521 & 389 & 242 & 262 & 168 & 251 & 254 & 170 & 139 & 120 & 104 & 101 & 56 & 38 & 38 \\
\hline 2 & 32 & 80 & 67 & 102 & 98 & 71 & 68 & 75 & 74 & 39 & 47 & 34 & 53 & 43 & 14 & 10 \\
\hline 3 & 30 & 79 & 53 & 64 & 44 & 63 & 55 & 48 & 56 & 27 & 45 & 21 & 15 & 29 & 4 & 14 \\
\hline 4 & 61 & 108 & 118 & 80 & 99 & 131 & 76 & 98 & 114 & 45 & 50 & 30 & 37 & 33 & 21 & 4 \\
\hline 5 & 18 & 45 & 54 & 56 & 60 & 71 & 71 & 102 & 87 & 59 & 74 & 45 & 75 & 46 & 37 & 42 \\
\hline 6 & 11 & 48 & 11 & 14 & 35 & 22 & 34 & 76 & 52 & 60 & 62 & 34 & 26 & 55 & 35 & 17 \\
\hline 7 & 12 & 15 & 13 & 16 & 36 & 48 & 49 & 92 & 79 & 57 & 72 & 27 & 33 & 30 & 19 & 16 \\
\hline 8 & 6 & 20 & 15 & 13 & 15 & 15 & 18 & 22 & 64 & 14 & 37 & 16 & 16 & 15 & 10 & 8 \\
\hline 9 & 22 & 5 & 4 & 4 & 4 & 4 & 4 & 15 & 28 & 10 & 26 & 16 & 11 & 14 & 6 & 7 \\
\hline 10 & 2 & 0 & 4 & 3 & 2 & 2 & 2 & 6 & 10 & 0 & 12 & 7 & 2 & 3 & 0 & 0 \\
\hline 11 & 2 & 6 & 11 & 0 & 1 & 1 & 2 & 6 & 4 & 2 & 0 & 0 & 1 & 3 & 1 & 0 \\
\hline 12 & 0 & 0 & 0 & 0 & 0 & 0 & 0 & 0 & 0 & 0 & 0 & 0 & 0 & 0 & 0 & 0 \\
\hline
\end{tabular}


TABle 5: Capacity utilization by sections and hours in a day for direction A.

\begin{tabular}{lcccccccccccccccc}
\hline \multicolumn{1}{c}{ Section } & $06.00-$ & $07.00-$ & $08.00-$ & $09.00-$ & $10.00-$ & $11.00-$ & $12.00-$ & $13.00-$ & $14.00-$ & $15.00-$ & $16.00-$ & $17.00-$ & $18.00-$ & $19.00-$ & $20.00-$ & $21.00-$ \\
& 07.00 & 08.00 & 09.00 & 10.00 & 11.00 & 12.00 & 13.00 & 14.00 & 15.00 & 16.00 & 17.00 & 18.00 & 19.00 & 20.00 & 21.00 & 22.00 \\
\hline 1 & 0.13 & 0.23 & 0.23 & 0.21 & 0.20 & 0.18 & 0.21 & 0.22 & 0.27 & 0.26 & 0.26 & 0.25 & 0.26 & 0.24 & 0.20 & 0.12 \\
2 & 0.13 & 0.24 & 0.23 & 0.22 & 0.20 & 0.20 & 0.22 & 0.23 & 0.25 & 0.25 & 0.25 & 0.25 & 0.27 & 0.24 & 0.22 & 0.13 \\
3 & 0.73 & 1.20 & 1.03 & 0.86 & 0.86 & 0.78 & 0.88 & 0.91 & 0.96 & 1.01 & 0.97 & 0.91 & 1.05 & 0.87 & 0.80 & 0.67 \\
4 & 0.33 & 1.40 & 1.11 & 0.97 & 1.04 & 0.85 & 1.06 & 1.02 & 1.26 & 1.27 & 1.04 & 1.19 & 1.27 & 1.36 & 1.14 & 0.65 \\
5 & 0.25 & 0.70 & 0.73 & 0.53 & 0.52 & 0.52 & 0.60 & 0.56 & 0.78 & 0.66 & 0.58 & 0.54 & 0.72 & 0.54 & 0.49 & 0.37 \\
6 & 0.33 & 0.63 & 0.65 & 0.55 & 0.56 & 0.58 & 0.56 & 0.57 & 0.60 & 0.54 & 0.54 & 0.65 & 0.64 & 0.64 & 0.49 & 0.39 \\
7 & 0.17 & 0.65 & 0.73 & 0.56 & 0.62 & 0.64 & 0.65 & 0.65 & 0.69 & 0.66 & 0.65 & 0.69 & 0.80 & 0.76 & 0.60 & 0.44 \\
8 & 0.14 & 0.51 & 0.54 & 0.42 & 0.47 & 0.55 & 0.51 & 0.51 & 0.56 & 0.52 & 0.51 & 0.54 & 0.65 & 0.62 & 0.34 & 0.22 \\
9 & 0.11 & 0.34 & 0.39 & 0.34 & 0.39 & 0.44 & 0.47 & 0.41 & 0.45 & 0.45 & 0.38 & 0.34 & 0.41 & 0.40 & 0.23 & 0.16 \\
10 & 0.28 & 0.79 & 0.99 & 0.83 & 0.94 & 0.98 & 1.17 & 1.00 & 1.07 & 1.07 & 0.89 & 0.78 & 0.97 & 0.96 & 0.61 & 0.41 \\
11 & 0.53 & 0.99 & 1.14 & 1.02 & 0.92 & 1.13 & 1.15 & 1.11 & 1.08 & 1.09 & 0.94 & 0.80 & 1.08 & 1.12 & 0.80 & 0.66 \\
12 & 0.38 & 0.82 & 1.14 & 1.10 & 1.23 & 1.48 & 1.11 & 1.24 & 1.07 & 1.19 & 0.93 & 0.74 & 1.04 & 1.23 & 1.10 & 0.69 \\
13 & 0.39 & 0.60 & 0.60 & 0.63 & 0.63 & 0.68 & 0.66 & 0.68 & 0.65 & 0.70 & 0.61 & 0.60 & 0.66 & 0.68 & 0.72 & 0.92 \\
14 & 0.63 & 1.02 & 1.19 & 1.13 & 1.37 & 1.33 & 1.26 & 1.26 & 1.19 & 1.26 & 1.11 & 1.06 & 1.21 & 1.16 & 1.31 & 0.95 \\
15 & 0.59 & 0.92 & 0.95 & 1.02 & 0.89 & 0.92 & 0.88 & 0.86 & 1.02 & 1.11 & 0.97 & 0.81 & 0.77 & 0.87 & 0.84 & 0.61 \\
\hline
\end{tabular}

TABLE 6: Capacity utilization by sections and hours in a day for direction B.

\begin{tabular}{lcccccccccccccccc}
\hline \multicolumn{1}{c}{ Section } & $06.00-$ & $07.00-$ & $08.00-$ & $09.00-$ & $10.00-$ & $11.00-$ & $12.00-$ & $13.00-$ & $14.00-$ & $15.00-$ & $16.00-$ & $17.00-$ & $18.00-$ & $19.00-$ & $20.00-$ & $21.00-$ \\
& 07.00 & 08.00 & 09.00 & 10.00 & 11.00 & 12.00 & 13.00 & 14.00 & 15.00 & 16.00 & 17.00 & 18.00 & 19.00 & 20.00 & 21.00 & 22.00 \\
\hline 1 & 0.59 & 0.95 & 0.87 & 0.83 & 0.91 & 0.88 & 0.88 & 0.85 & 0.88 & 0.85 & 0.81 & 0.72 & 0.77 & 0.74 & 0.68 & 0.60 \\
2 & 0.45 & 0.96 & 0.93 & 0.98 & 1.01 & 0.98 & 0.97 & 1.03 & 0.96 & 1.00 & 0.95 & 0.62 & 0.67 & 0.68 & 0.54 & 0.52 \\
3 & 0.80 & 1.08 & 1.06 & 0.93 & 1.11 & 1.08 & 1.01 & 0.98 & 1.04 & 1.05 & 0.94 & 1.03 & 1.09 & 1.05 & 1.00 & 0.72 \\
4 & 0.68 & 1.00 & 0.99 & 0.99 & 0.95 & 0.98 & 0.96 & 0.87 & 0.84 & 0.88 & 0.81 & 0.88 & 0.97 & 0.93 & 0.85 & 0.67 \\
5 & 0.36 & 0.79 & 0.85 & 0.83 & 0.77 & 0.83 & 0.86 & 0.89 & 0.83 & 0.86 & 0.77 & 0.71 & 0.72 & 0.68 & 0.59 & 0.53 \\
6 & 0.12 & 0.33 & 0.40 & 0.33 & 0.34 & 0.44 & 0.42 & 0.41 & 0.34 & 0.34 & 0.29 & 0.27 & 0.36 & 0.37 & 0.29 & 0.23 \\
7 & 0.22 & 0.59 & 0.71 & 0.58 & 0.56 & 0.63 & 0.62 & 0.62 & 0.74 & 0.74 & 0.54 & 0.54 & 0.71 & 0.71 & 0.52 & 0.41 \\
8 & 0.29 & 0.79 & 0.85 & 0.72 & 0.69 & 0.75 & 0.62 & 0.62 & 0.73 & 0.67 & 0.55 & 0.52 & 0.77 & 0.76 & 0.50 & 0.32 \\
9 & 0.21 & 0.59 & 0.42 & 0.54 & 0.53 & 0.55 & 0.48 & 0.48 & 0.54 & 0.51 & 0.42 & 0.42 & 0.57 & 0.55 & 0.40 & 0.24 \\
10 & 0.29 & 0.50 & 0.52 & 0.58 & 0.60 & 0.65 & 0.55 & 0.66 & 0.70 & 0.69 & 0.62 & 0.73 & 0.69 & 0.68 & 0.55 & 0.41 \\
11 & 0.26 & 0.65 & 0.75 & 0.73 & 0.89 & 0.76 & 0.76 & 0.80 & 0.93 & 1.02 & 0.80 & 0.64 & 0.69 & 0.83 & 0.61 & 0.50 \\
12 & 0.40 & 0.59 & 0.73 & 0.68 & 0.65 & 0.48 & 0.60 & 0.50 & 0.83 & 0.84 & 0.65 & 0.77 & 0.70 & 0.67 & 0.64 & 0.62 \\
13 & 0.24 & 0.41 & 0.41 & 0.36 & 0.38 & 0.33 & 0.34 & 0.36 & 0.46 & 0.46 & 0.43 & 0.44 & 0.46 & 0.45 & 0.44 & 0.31 \\
14 & 0.14 & 0.25 & 0.25 & 0.23 & 0.22 & 0.18 & 0.19 & 0.22 & 0.32 & 0.32 & 0.31 & 0.29 & 0.30 & 0.30 & 0.29 & 0.28 \\
15 & 0.10 & 0.22 & 0.20 & 0.18 & 0.18 & 0.15 & 0.16 & 0.21 & 0.23 & 0.27 & 0.24 & 0.22 & 0.25 & 0.23 & 0.21 & 0.20 \\
\hline
\end{tabular}

TABle 7: Travel time in direction A, obtained in the model.

\begin{tabular}{lcccc}
\hline Hours & $t_{r}(\min )$ & $t_{s}(\min )$ & $d(\min )$ & $T_{T}(\min )$ \\
\hline $6.00-7.00$ & 10.7 & 2.2 & 3.6 & 16.5 \\
$7.00-8.00$ & 13.5 & 5.1 & 6.1 & 24.7 \\
$8.00-9.00$ & 14.2 & 4.4 & 5.3 & 23.9 \\
$9.00-10.00$ & 13.7 & 4.0 & 4.9 & 22.6 \\
$10.00-11.00$ & 13.4 & 6.5 & 4.9 & 24.8 \\
$11.00-12.00$ & 13.4 & 5.7 & 4.8 & 23.9 \\
$12.00-13.00$ & 13.8 & 8.4 & 5.0 & 27.2 \\
$13.00-14.00$ & 13.8 & 8.0 & 4.9 & 26.7 \\
$14.00-15.00$ & 14.3 & 6.9 & 6.4 & 27.6 \\
$15.00-16.00$ & 14.3 & 6.7 & 6.3 & 27.3 \\
$16.00-17.00$ & 13.6 & 7.2 & 5.0 & 25.8 \\
$17.00-18.00$ & 12.7 & 4.9 & 5.3 & 22.9 \\
$18.00-19.00$ & 14.0 & 6.5 & 5.3 & 25.8 \\
$19.00-20.00$ & 13.8 & 5.3 & 4.9 & 24.0 \\
$20.00-21.00$ & 13.0 & 4.3 & 3.9 & 21.2 \\
$21.00-22.00$ & 11.7 & 2.1 & 3.6 & 17.4 \\
\hline
\end{tabular}

TABLe 8: Travel time in direction B, obtained in the model.

\begin{tabular}{lcccc}
\hline Hours & $t_{r}(\min )$ & $t_{s}(\min )$ & $d(\min )$ & $T_{T}(\min )$ \\
\hline $6.00-7.00$ & 10.7 & 2.9 & 4.6 & 18.2 \\
$7.00-8.00$ & 12.9 & 4.3 & 5.7 & 22.9 \\
$8.00-9.00$ & 12.8 & 4.4 & 5.8 & 23.0 \\
$9.00-10.00$ & 12.6 & 4.4 & 6.0 & 23.0 \\
$10.00-11.00$ & 12.9 & 4.8 & 6.4 & 24.1 \\
$11.00-12.00$ & 12.8 & 5.4 & 7.1 & 25.3 \\
$12.00-13.00$ & 12.7 & 5.4 & 7.0 & 25.0 \\
$13.00-14.00$ & 12.6 & 5.9 & 6.6 & 25.1 \\
$14.00-15.00$ & 12.8 & 5.2 & 6.8 & 24.9 \\
$15.00-16.00$ & 13.2 & 3.4 & 7.7 & 24.3 \\
$16.00-17.00$ & 12.1 & 5.2 & 5.4 & 22.7 \\
$17.00-18.00$ & 11.8 & 2.7 & 4.0 & 18.5 \\
$18.00-19.00$ & 12.1 & 3.3 & 4.8 & 20.2 \\
$19.00-20.00$ & 12.0 & 3.6 & 4.5 & 20.1 \\
$20.00-21.00$ & 11.5 & 2.3 & 3.3 & 17.1 \\
$21.00-22.00$ & 10.8 & 1.9 & 3.0 & 15.7 \\
\hline
\end{tabular}




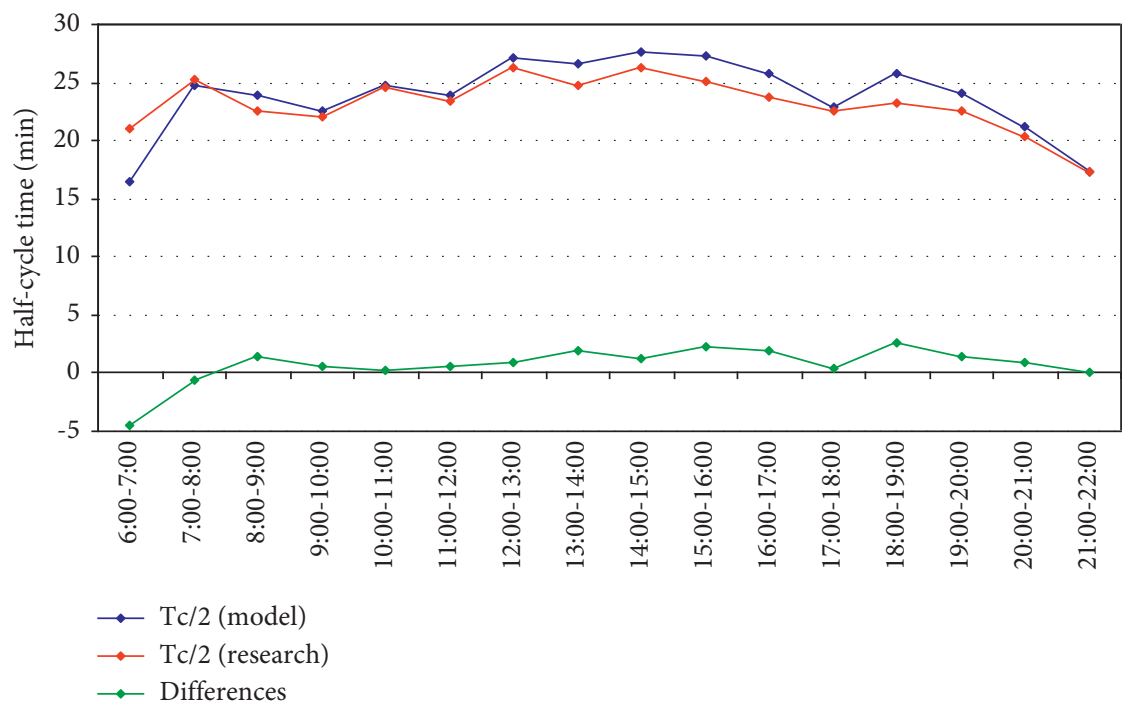

FIGURE 9: Comparative review of the realized values of the travel time and the values obtained in the model and differences between the two, by hours in a day, for direction $\mathrm{A}$.

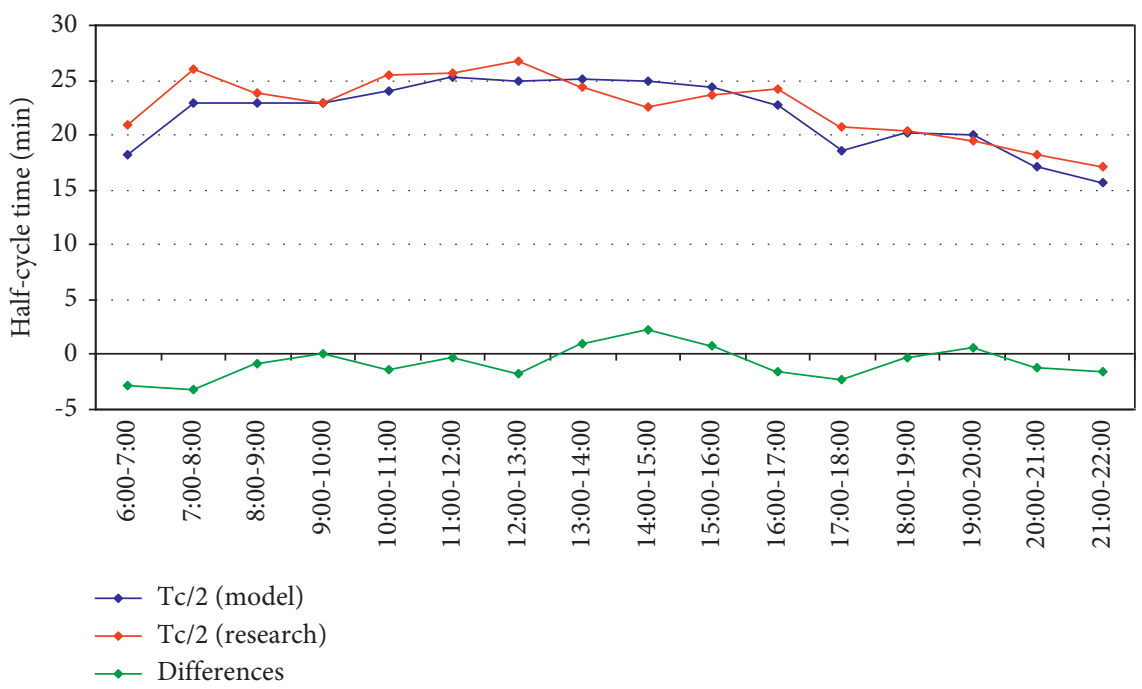

Figure 10: Comparative review of the realized values of the travel time and the values obtained in the model and differences between the two, by hours in a day, for direction B.

TABLe 9: Deviation of the simulated values of PT vehicles' travel time from the real values of PT travel time.

\begin{tabular}{llccc}
\hline Data source & & RMSNE & CC & MAPS (\%) \\
\hline Direction A & Simulated data & 0.077 & 0.88 & 4.32 \\
Direction B & Simulated data & 0.072 & 0.88 & 4.37 \\
\hline
\end{tabular}

during the day, on an average day on line 4 by applying the proposed model, the savings could be achieved regarding the expenses generated by a vehicle in the period of 12 operating hours. The total transport work achieved by a vehicle in the period of 12 operating hours on line 4 is $133.8 \mathrm{~km}$. Reduction in travel time positively affects operating costs, primarily fuel costs. In the period when the research study was conducted, the PT vehicles in Novi Sad mostly used diesel; thus, the analysis of savings was done for this type of fuel. Reduction of fuel consumption affects the reduction of external costs, that is, costs occurring with the emission of all types of pollutants. Since $\mathrm{CO}_{2}$ has the greatest impact on greenhouse effect, when calculating the cost reduction, only the reduction of this pollutant's emission was considered. Direct annual savings in the time of the engagement of the vehicle and the driver, the consumption of fuel, and $\mathrm{CO}_{2}$ emission are shown in Table 11.

When calculating cost reduction by applying the proposed model, the reduction of all operating business costs regarding the reduction of the driver's working hours was not considered. Namely, by applying the proposed model, the reduction of the driver's engagement can be achieved with the change in the organization of the driver's work on 


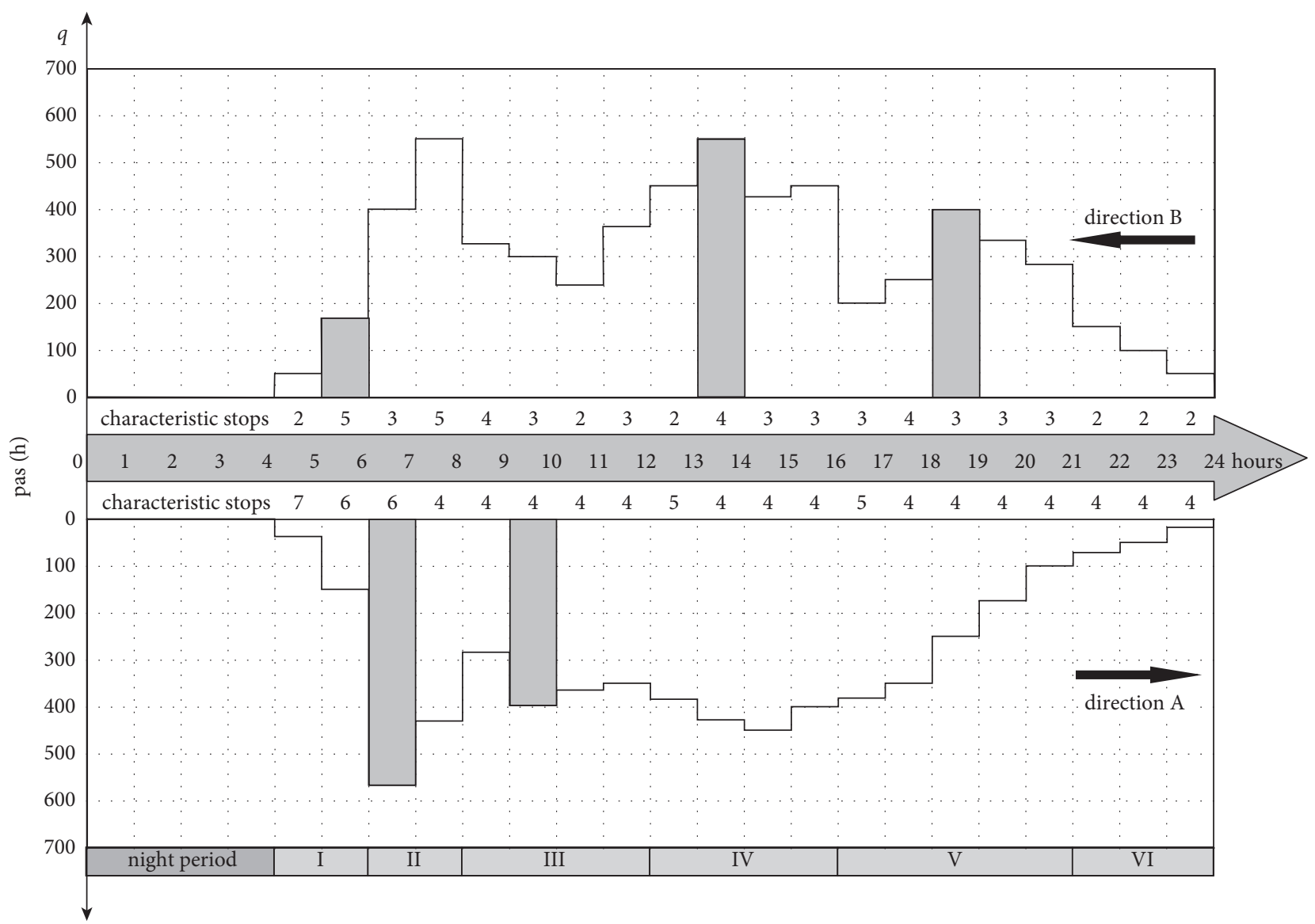

Figure 11: Typical periods of public transport vehicles operating during the day [46].

TABLE 10: Comparative analysis of the necessary number of vehicles for the existing duration of the cycle, as well as during the cycle time obtained in the model.

\begin{tabular}{|c|c|c|c|c|c|c|c|}
\hline \multirow{2}{*}{ Periods } & \multicolumn{3}{|c|}{ Operating with the constant cycle time } & \multicolumn{3}{|c|}{ Operating with the changeable cycle time } & \multirow{2}{*}{ Difference } \\
\hline & Cycle time & Intervals & Number of vehicles & Cycle time & Intervals & Number of vehicles & \\
\hline $\mathrm{I}$ & 60 & 12 & 5 & 40 & 12 & 4 & 1 \\
\hline II & 60 & 6 & 10 & 50 & 6 & 9 & 1 \\
\hline III & 60 & 7.5 & 8 & 60 & 7.5 & 8 & 0 \\
\hline IV & 60 & 6 & 10 & 60 & 6 & 10 & 0 \\
\hline $\mathrm{V}$ & 60 & 7.5 & 8 & 50 & 7.5 & 7 & 1 \\
\hline VI & 60 & 12 & 5 & 40 & 12 & 4 & 1 \\
\hline
\end{tabular}

other lines as well, which was not the subject of the research in this paper. When calculating the savings, the following savings were not considered: fleet maintenance savings, costs of the reduction of the necessary number of vehicles, administrative costs, etc. which can be objectively assessed after the analysis of all lines and the complete system of public transport.

\section{Advantages and Limitations of the Model}

The biggest advantage of the developed model is the possibility of its practical application in public transport system. Thanks to the developed model, it is possible to change the previous practice of the calculation of the elements of PT vehicles operating based only on the characteristics of the line of public transport for which the schedule is being made and the referential number of passengers. By applying the developed model, it is possible to establish a new concept of schedule creating which will consider traffic conditions. In favor of this research, there is a fact that the realized elements of PT vehicles operating obtained in the research study on line 4 significantly differ from the operating elements designed when schedule was created. Taking into consideration the conditions of traffic and applying the model to the whole system of public transport would induce significant savings due to the possibility of the reduction of the 


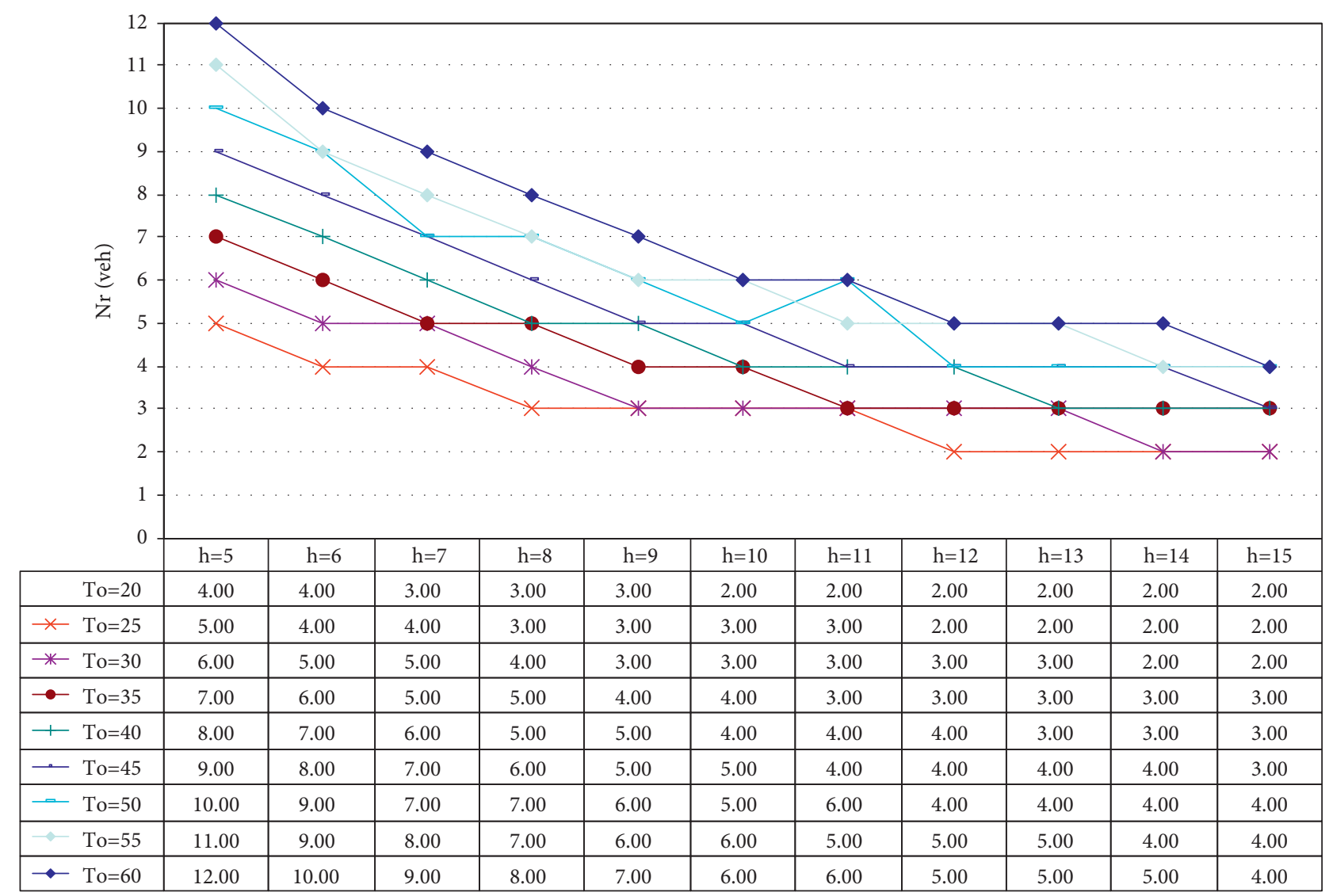

Figure 12: Change of the number of operating vehicles in the function of cycle time.

TABLE 11: Annual savings which would be achieved by applying the proposed model on line 4 .

\begin{tabular}{lcc}
\hline Savings & Amount & Value (EUR) \\
\hline Driving time & $4,380(\mathrm{~h})$ & 29,550 \\
Fuel consumption & $25,834(\mathrm{~kg})$ & 27,450 \\
$\mathrm{CO}_{2}$ consumption & $68,950(\mathrm{~kg})$ & 3,450 \\
Total & & 60,450 \\
\hline
\end{tabular}

number of vehicles, number of employees, fuel consumption, etc.

The greatest importance of applying this model is reflected in the design of elements of PT vehicles operating when introducing new surface systems or when changing the routes of certain lines in the system for road work on certain arterials, different sport events (marathon, cycling races, etc.) and other manifestations, change of the purpose of the surface which causes a new distribution of origin-destination travel, etc.

The problem with applying this new model can occur in undeveloped environments where there is no continuous monitoring of the parameters of traffic flow in the street network. In the situation when the flow demand is unknown, which is the condition for the model applying, it is not possible to determine travel time by applying this model. Previous to applying the model, it is necessary to check the following parameters by means of direct research: (i) PT vehicles hindering when exiting the bus stop

(ii) PT vehicles delay at bus stop

(iii) The value of deceleration when stopping the vehicle at the bus stop

(iv) The value of acceleration when PT vehicles exit the bus stop

(v) The influence of roundabouts, if there are any on the line of public transport

(vi) The model cannot be applied for "F" level of service, that is, the situations when the flow demand is higher than the capacity of the street network

(vii) The influence of the human factor, that is, the manner of driving

\section{Conclusions}

Due to the flexibility and possibility of street network utilization, bus massive passenger transport in cities is one of the key factors of sustainable urban mobility. On most lines in urban areas, bus transport is carried out in mixed traffic conditions; therefore, this transport is exposed to traffic changes. For the sake of maintenance of the planned operational elements, operators plan cycle time for the conditions of the highest street network volume. In this way, the number of vehicles operating on the lines of public transport is larger than really necessary, in the conditions of low and 
medium street network volume. The larger the number of public transport vehicles on the lines, the higher the operating costs and the emission of pollutants.

In order for public transport which functions in mixed traffic conditions to become more efficient, when determining operating elements, it is necessary to take into consideration the variables which affect it. This paper aims to develop an analytical model for determining the optimum number of vehicles on public transport lines, which will be in accordance with traffic flow unevenness, in order to meet the set criterion for the quality of transport service. The analytical model determines travel time, considering traffic flow parameters, characteristics of line routes, demands of the passengers who use public transport, etc. Cycle time and consequently travel time constitute a starting parameter for determining the number of vehicles which are to operate on public transport lines, as well as all other elements. The optimization model has been developed so as to make public transport system more efficient, both economically and environmentally.

The developed model is based on the traffic flow parameters, the speed, and the flow related to capacity utilization. Apart from that, travel time is also affected by terminal dwell time, which is also an integral part of the model. The model has been complemented by considering all signalized and unsignalized intersections on the vehicles' way along the route, that is, delays which occur due to their going through the intersection. Taking into consideration all previously stated parameters, it is possible to calculate travel time of the bus (real time of cycle time) which functions in mixed traffic conditions. The model represents a significant contribution to the research of travel time in the mixed traffic flow, since, according to the review of the literature in their paper in 2020, Harsha et al. [8] concluded that most research studies are carried out in the countries which have almost homogeneous traffic conditions.

The developed analytical model was tested with real data in the work conditions of one typical city line. The data necessary for testing were obtained in the research of parameters in the real traffic network and on one selected city line of public transport. Comparative analysis of real operating elements on the experimental line, with the operating elements of the obtained model, implies that the modeled values are in accordance with the values realized in real conditions. The model has also shown that it is possible to reduce the number of vehicles operating on certain lines of public transport in certain periods of the day, when there is a low or medium street network volume. By means of comparative analysis, it was also determined that the reduction of the number of the operating vehicles does not affect the quality of service in public transport; that is, transport capacities and headways remain unchanged.

The operator who was carrying out the transport on the experimental line took the cycle time as the fixed value regardless of the operating period in the day and traffic conditions. Cycle time during the whole day was adopted for the most unfavorable conditions of peak street network volumes. The parameters which affect operating elements of lines are changeable during the day, and with the model the interdependence of operating elements and the researched parameters was obtained. With the model, it is possible to determine optimal operating elements depending on parameters' influence. Depending on the expected or previously defined typical periods, it is possible to plan operating elements which are changeable in typical periods during the day, as well as on certain days of a week.

The savings which are achieved have been quantified through the reduction of the number of operating vehicles, whereby it was concluded that they can be significant at certain time periods. By applying the model to the whole system of public transport on a certain area, the effects would be even more favorable. The reason for this is that in that case the reduction of costs related to fleet maintenance, as well as investment and administrative costs of the system operating, would occur. The advantage of the developed model, which includes traffic conditions in the calculation of travel time, enables the achievement of significant savings. Practical application of the model enables the planning of PT vehicles operating, which will be in accordance with real conditions of traffic where PT vehicles move in accordance with spatial and time variabilities of traffic flow.

For further research studies, it is recommended that research on the influence of pedestrian flows on travel time of PT vehicles is conducted since certain delays occur as a consequence of allowing pedestrians to cross the road at pedestrian crossings. It is also necessary to research the influence of buses' delays at bus stops when simultaneously more PT vehicles arrive from different lines, which can cause additional delay of the vehicles at stops.

\section{Data Availability}

All the data (characteristics of the stops of line 4; passengers' entries by bus stops; capacity utilization; bus travel times) used to support the findings of this study are included within the article.

\section{Conflicts of Interest}

The authors declare that there are no conflicts of interest regarding the publication of this paper.

\section{Acknowledgments}

This research was partly financed by the Ministry of Education, Science and Technological Development of the Republic of Serbia (project ID: NIO200156, project name: Innovative Scientific and Artistic Research in the Field of Faculty of Technical Sciences Activities).

\section{References}

[1] M. Ogryzek, D. Adamska-Kmieć, and A. Klimach, "Sustainable transport: an efficient transportation network-case study," Sustainability, vol. 12, p. 8274, 2020.

[2] U. Mori, A. Mendiburu, M. Álvarez, and J. A. Lozano, "A review of travel time estimation and forecasting for advanced traveller information systems," Transportmetrica A: Transport Science, vol. 11, pp. 119-157, 2015. 
[3] ACEA European Automobile Manufacturers' Association Available Online: https://www.acea.be/automobile-industry/ buses.

[4] V. Stjernborg and O. Mattisson, "The role of public transport in society - a case study of general policy documents in Sweden," Sustainability, vol. 8, p. 1120, 2016.

[5] Development of SEAP Novi Sad for the Project "Renewable Solar Energy" Interreg IPA CBC XXIV-351-2903/17-1062/3; Novi Sad, 2018.

[6] M. M. Nesheli, A. Ceder, F. Ghavamirad, and S. Thacker, "Environmental impacts of public transport systems using real-time control method," Transportation Research Part D: Transport and Environment, vol. 51, pp. 216-226, 2017.

[7] B. Büchel and F. Corman, "Review on statistical modeling of travel time variability for road-based public transport," Frontiers in Built Environment, vol. 6, 2020.

[8] M. M. Harsha, R. H. Mulangi, and H. D. D. Kumar, “Analysis of bus travel time variability using automatic vehicle location data," Transportation Research Procedia, vol. 48, pp. 32833298, 2020.

[9] J. Ma, J. Chan, G. Ristanoski, S. Rajasegarar, and C. Leckie, "Bus travel time prediction with real-time traffic information," Transportation Research Part C: Emerging Technologies, vol. 105, pp. 536-549, 2019.

[10] M. Gentili and P. B. Mirchandani, "Review of optimal sensor location models for travel time estimation," Transportation Research Part C: Emerging Technologies, vol. 90, pp. 74-96, 2018.

[11] C. E. McKnight, H. S. Levinson, K. Ozbay, C. Kamga, and R. E. Paaswell, "Impact of traffic congestion on bus travel time in northern New Jersey," Transportation Research Record: Journal of the Transportation Research Board, vol. 1884, pp. 27-35, 2004.

[12] R. Pye and C. Bodé, "Demonstrating intensive bus priority," Traffic Engineering and Control, vol. 46, pp. 404-409, 2005.

[13] R. Fernandez and A. Valencia, "Traffic management method to study bus priorities on arterial roads," in Proceedings of the European Transport Conference 2012, pp. 1-17, Association for European Transport and Contributors, Glasgow, Scotland, 2012.

[14] K. Birr, K. Jamroz, and W. Kustra, "Travel time of public transport vehicles estimation," Transportation Research Procedia, vol. 3, pp. 359-365, 2014.

[15] A. Tirachini and D. A. Hensher, "Bus congestion, optimal infrastructure investment and the choice of a fare collection system in dedicated bus corridors," Transportation Research Part B: Methodological, vol. 45, pp. 828-844, 2011.

[16] A. Tirachini, D. A. Hensher, and J. M. Rose, "Multimodal pricing and optimal design of urban public transport: the interplay between traffic congestion and bus crowding," Transportation Research Part B: Methodological, vol. 61, pp. 33-54, 2014.

[17] A. Chepuri, C. Kumar, P. Bhanegaonkar, S. S. Arkatkar, and G. Joshi, "Travel time reliability analysis on selected bus route of mysore using GPS data," Transportation in Developing Economies, vol. 5, p. 13, 2019.

[18] W. Suwardo, M. Napiah, and I. Kamaruddin, "On-time performance and service regularity of stage buses in mixed traffic," International Journal of Economics, Finance and Management Sciences, vol. 1, no. 3, pp. 176-183, 2009.

[19] Y. Zhou, L. Yao, Y. Chen, Y. Gong, and J. Lai, "Bus arrival time calculation model based on smart card data," Transportation Research Part C: Emerging Technologies, vol. 74, pp. 81-96, 2017.
[20] V. Vuchic, Urban Transport Operation, Planning and Economics, John Wiley \& Sons Inc., Hoboken, NJ, USA, 2005.

[21] D. Marković, G. Petrovć, Ž. Ćojbašić, and A. Stanković, "The vehicle routing problem with stochastic demands IN an urban area-a case study," Facta Universitatis-Series: Mechanical Engineering, vol. 18, p. 107, 2020.

[22] M. M. Rahman, S. C. Wirasinghe, and L. Kattan, "Analysis of bus travel time distributions for varying horizons and realtime applications," Transportation Research Part C: Emerging Technologies, vol. 86, pp. 453-466, 2018.

[23] S. Tao, J. Corcoran, F. Rowe, and M. Hickman, "To travel or not to travel: 'weather' is the question. Modelling the effect of local weather conditions on bus ridership," Transportation Research Part C: Emerging Technologies, vol. 86, pp. 147-167, 2018.

[24] B. A. Kumar, L. Vanajakshi, and S. C. Subramanian, "Bus travel time prediction using a time-space discretization approach," Transportation Research Part C: Emerging Technologies, vol. 79, pp. 308-332, 2017.

[25] R. Kuhne, "Foundations of traffic flow theory I: greenshields' legacy-highway traffic," in Proceedings of the Symposium on the Fundamental Diagram: 75 Years (Greenshields 75 Symposium); Transportation Research Board, vol. E-C149, p. 134, Woods Hole, MA, USA, July 2008.

[26] H. Rakha and Y. Gao, "Calibration of steady-state car-following models using macroscopic loop detector data," in Proceedings of the Symposium on the Fundamental Diagram: 75 Years (Greenshields 75 Symposium); Transportation Research Board, p. 24, Woods Hole, MA, USA, 2008.

[27] H. K. Sharma, M. Swami, and B. L. Swami, "Speed-flow analysis for interrupted oversaturated traffic flow with heterogeneous structure for urban roads," International Journal of Traffic and Transportation Engineering, vol. 2, pp. 142-152, 2012.

[28] F. L. Hall, N. Gartner and C. J. Messer, Traffic stream characteristics," in Traffic Flow Theory. A State-Of-the-Art Reportp. 31, University of Massachusetts Lowell, Lowell, MA, USA, 2001.

[29] N. R. Council, "TRB highway capacity manual," 2000.

[30] P. T. Blythe, "Improving public transport ticketing through smart cards," Proceedings of the Institution of Civil Engineers: Municipal Engineer, vol. 157, pp. 47-54, 2004.

[31] H. Iseki, A. Demisch, B. D. Taylor, and A. C. Yoh, "Evaluating the costs and benefits of transit smart cards," 2008.

[32] M.-P. Pelletier, M. Trépanier, and C. Morency, "Smart card data use in public transit: a literature review," Transportation Research Part C: Emerging Technologies, vol. 19, pp. 557-568, 2011.

[33] A. Tirachini, "Estimation of travel time and the benefits of upgrading the fare payment technology in urban bus services," Transportation Research Part C: Emerging Technologies, vol. 30, pp. 239-256, 2013.

[34] P. White, M. Bagchi, H. Bataille, and S. M. East, "The role of smartcard data in public transport," in Proceedings of the 12th World Conference on Transport Research, pp. 1-16, Lisbon, Portugal, July 2010.

[35] M. Simeunović, P. Pitka, and M. Simeunović, "The influence of an electronic payment system on decreased vehicle dwell time at stops," in Proceedings of the IV International Conference "Towards a Humane City", pp. 385-392, Department for traffic engineering, Faculty of technical sciences, University of Novi Sad, Novi Sad, Serbia, 2013.

[36] V. Vukan, Urban Transit Systems and Technology, John Viley \& Sons Inc., Hoboken, NJ, USA, 2007. 
[37] A. Khadhir, H. Maripini, S. Sreedhar, L. Vanajakshi, and B. R. Chilukuri, "A study of delay estimation methods at signalized intersections for mixed traffic condition," Transportation in Developing Economies, vol. 7, pp. 1-16, 2021.

[38] Faculty of Technical Sciences; Adomne Smart Plan-The First Phase; Novi Sad, Serbia, 2018.

[39] FDOT Systems Planning Office, Traffic Analysis Handbook: A Reference for Planning and Operations, FDOT Systems Planning Office, Tallahassee, FL, USA, 2014.

[40] B. Y. Chen, Y. Wang, D. Wang, and W. H. K. Lam, "Understanding travel time uncertainty impacts on the equity of individual accessibility," Transportation Research Part D: Transport and Environment, vol. 75, pp. 156-169, 2019.

[41] K. Fransen, T. Neutens, S. Farber, P. De Maeyer, G. Deruyter, and F. Witlox, "Identifying public transport gaps using timedependent accessibility levels," Journal of Transport Geography, vol. 48, pp. 176-187, 2015.

[42] N. Wessel, J. Allen, and S. Farber, "Constructing a routable retrospective transit timetable from a real-time vehicle location feed and GTFS," Journal of Transport Geography, vol. 62, pp. 92-97, 2017.

[43] E. Mazloumi, G. Currie, and G. Rose, "Using GPS data to gain insight into public transport travel time variability," Journal of Transportation Engineering, vol. 136, pp. 623-631, 2010.

[44] Z. Ma, L. Ferreira, M. Mesbah, and S. Zhu, "Modeling distributions of travel time variability for bus operations," Journal of Advanced Transportation, vol. 50, pp. 6-24, 2016.

[45] R. Chase, B. Williams, and N. Rouphail, "Detailed analysis of travel time reliability performance measures from empirical data," in Proceedings of the Transportation Research Board 92nd Annual Meeting, Washington, DC, USA, January 2013.

[46] R. Banković, Organization and Technology of Public Urban Passenger Transport, Faculty of Transport and Traffic Engineering, Belgrade, Serbia, 1994. 